\title{
MiR-29b-3p affects growth and biological functions of human extravillous trophoblast cells by regulating bradykinin $\mathrm{B} 2$ receptor
}

Likui Wang, Yunguang Li

Department of Obstetrics and Gynecology, Qilu Hospital of Shandong University, Wenhua Xi Road, Ji'nan City, Shandong, China

Submitted: 10 April 2019; Accepted: 5 May 2019

Online publication: 10 January 2020

Arch Med Sci 2022; 18 (2): 499-522

DOI: https://doi.org/10.5114/aoms.2019.91512

Copyright @ 2019 Termedia \& Banach

\section{Abstract}

Introduction: This study investigated miR-29b-3p's effects and mechanisms in preeclampsia development.

Material and methods: In this study, we analysed the pathology and expression of miR-29b-3p and B2R mRNA from normal and preeclampsia placenta tissues using hematoxylin and eosin staining and RT-qPCR assay. For cell experiments, we used transwell assay CCK-8, flow cytometry and wound healing assay to determine the effects and correlation of miR-29b-3p and B2R in HTR-8/SVneo cell proliferation, apoptosis, cell cycle, cell invasion and migration in a preeclampsia cell model. Moreover, the mechanisms were determined using Western blot or immunofluorescence in different groups. Results: Clinical analysis revealed that miR-29b-3p gene expression dramatically increased with increasing degree of preeclampsia $(p<0.001$ or $p<0.05$, respectively). The HTR-8/SVneo cell biological activities of the model group were significantly depressed $(p<0.001)$. However, with miR-29b-3p inhibitor or B2R transfection, the HTR-8/SVneo cell biological activities significantly recovered $(p<0.001)$. Western blot assay showed that B2R, VEGF-A, CCND-1, MMP-2 and MMP-9 levels were suppressed in the model group, compared with those in the NC groups ( $p<0.001$, respectively). With miR-29b-3p inhibitor or B2R transfection, the protein expression levels of B2R, VEGF-A, CCND-1, MMP-2 and MMP-9 dramatically increased ( $p<0.001$, respectively). Conclusions: The down-regulation of miR-29b-3p could improve HTR-8/SVneo cell biological activities in a preeclampsia cell model by targeting B2R.

Key words: miR-29b-3p, HTR-8/SVneo cell, B2R, preeclampsia, biological activities.

\section{Introduction}

Extravillous trophoblasts are an important component of the placenta having a key role in placenta development [1]. Abnormal growth and function of extravillous trophoblasts may lead to disorders in placenta formation, causing a range of pregnancy-related diseases. Insufficient trophoblast invasion can cause miscarriage, fetal growth restriction and preeclampsia (PE) [2], whereas excessive invasion can cause placental adhesions and implantation [3]. The proliferation and invasion of extravillous trophoblasts are strictly regulated by a series of molecules. Some

\author{
Corresponding author: \\ Yunguang Li \\ Department \\ of Obstetrics and \\ Gynecology \\ Qilu Hospital \\ of Shandong University \\ Wenhua Xi Road \\ Ji'nan City, Shandong \\ China \\ E-mail: liyunguang0120@ \\ hotmail.com
}


positive regulators, such as matrix metalloproteinase (MMP)-2 and MMP-9, promote the migration and invasion of extravillous trophoblasts [4], whereas some negative regulators, such as miRNA-155, can inhibit their migration and invasion [5]. Studies have shown that the expression of bradykinin B2 receptor (B2R) is significantly reduced in extravillous trophoblast patients with $P E$ [6]. Continuous subcutaneous injection of a B2R antagonist (bradyzide) can cause a transient increase in systolic blood pressure in guinea pigs in early pregnancy, and can lead to restricted progeny growth and reduced trophoblast invasion in the spiral artery [7]. In the $G$ protein-coupled receptor superfamily, B2R has an important role and participates in various biological processes, mainly by binding to bradykinin and activating downstream signalling pathways. Relevant studies have suggested that miRNAs can inhibit the biological activity of tumour cells by regulating B2R [8-10]. These studies suggested that miRNAs targeting B2R may be closely related to the proliferation and invasion of extravillous trophoblasts in early pregnancy. However, the direct involvement of miRNAs targeting B2R in the supervision of cell function has not been explicitly reported. Our present study discussed the effect and possible systems of B2R-targeting miRNA-29b-3p on the biological behaviour of the human early-pregnancy extravillous trophoblast cell line HTR-8/SVneo.

\section{Material and methods}

\section{Clinical samples}

Placenta tissues were collected between June 2016 and March 2018 from 30 normal controls and 30 patients with $\mathrm{PE}$, including 20 mild cases and 10 severe cases in Qilu Hospital of Shandong University. The collected samples were stored at $-80^{\circ} \mathrm{C}$ before 2017.12 and new samples were stored at $-20^{\circ} \mathrm{C}$. This study protocol was approved by the ethics committee of Qilu Hospital of Shandong University, and all subjects included in the study signed the informed consent.

\section{Cells and reagents}

The cell line used in this study was the immortalised human early-pregnancy extravillous trophoblast cell line HTR-8/SVneo, which was provided by ATCC. RPMI 1640 medium, foetal bovine serum (FBS), ethylenediaminetetraacetic acid (EDTA), penicillin and streptomycin were purchased from Gibco (USA). Lipofectamine 3000 was purchased from Thermo Fisher (USA). The RNA extraction reagent Trizol was purchased from Beijing Tiangen Biochemical Technology Co., Ltd. 5X All-In-One RT Master Mix reverse transcription reagent was purchased from Shanghai Yudu Bio- technology Co., Ltd. SYBR Green Supermix was purchased from Nanjing Vazyme Company. Primers for B2R, MMP-2, MMP-9, cyclin-1 (CCND-1), vascular endothelial growth factor-A (VEGF-A) and glyceraldehyde-3-phosphate dehydrogenase (GAPDH) were purchased from Shanghai Ruizhen Biotechnology Co., Ltd. Cell Counting Kit-8 (CCK-8) was purchased from the Dojindo Laboratories (Japan). Artificial basement membrane Matrigel was purchased from BD Biosciences (USA). Transwell chambers were purchased from Millipore (USA). Antibodies against B2R, VEGF-A, CCND-1, MMP-2, MMP-9 and GAPDH were purchased from $A b$ cam (UK). Negative control small interfering RNA (siRNA) sequence 5'-UGGUUUACAUGUUUUCUGA-3', B2R-specific siRNA sequence 5'-GGCAGAGGAAGAUAUUUCU-3', miR-29b-3p inhibitor sequence 5'-AACACUGAUUUCAAAUGGUGCUA-3' and si-NC sequence 5'-CACUGAUUUCAAAUGGUGCUAUU-3' were purchased from Guangzhou Ruibo Biotechnology Co., Ltd. The pcDNA 3.1 and pcDNA 3.1-B2R plasmids were provided by Shanghai Jierui Bioengineering Co., Ltd.

\section{Sample collection}

Several pieces of placental tissue, about $1 \mathrm{~cm}^{3}$ in total volume, were collected within $1 \mathrm{~min}$ after placenta delivery under sterile conditions from the mother's side away from calcified plaques. The samples were washed with normal saline twice and were stored at $-80^{\circ} \mathrm{C}$ for a long time or fixed in $4 \%$ paraformaldehyde at $4^{\circ} \mathrm{C}$ for $24 \mathrm{~h}$, dehydrated, cleared, paraffinised, embedded, sectioned into $5 \mu \mathrm{m}$ slices and stored in $\mathrm{a}-20^{\circ} \mathrm{C}$ refrigerator.

\section{HE staining}

The slices were baked at $55^{\circ} \mathrm{C}$ for $1 \mathrm{~h}$, dewaxed, hydrated, stained with haematoxylin, blued with ammonia, stained with eosin, dehydrated, cleared, sealed with neutral resin and observed under a microscope.

\section{Cell cultivation}

RPMI 1640 medium containing 10\% FBS, with $100 \mathrm{U} / \mathrm{ml}$ penicillin and $100 \mathrm{mg} / \mathrm{ml}$ streptomycin, was used to cultured cells in a $5 \% \mathrm{CO}_{2}$ incubator at $37^{\circ} \mathrm{C} .1-2$ days later, the cells were digested with $0.25 \%$ trypsin-EDTA solution and sub-cultured at $1: 2$ to $1: 3$. The cells were inoculated into culture plates for subsequent experiments when they reached $70-90 \%$ confluence.

\section{Cell transfection}

HTR-8/SVneo cells were seeded in culture plates at $2 \times 10^{5}$ cells $/ \mathrm{ml}$. When cell confluence reached 
50-70\%, transfection was carried out with Lipofectamine 3000 following the instructions.

\section{RT-qPCR assay}

After thorough mixing, the cells were lysed by adding $1 \mathrm{ml}$ of Trizol reagent, and the total RNA was extracted according to the instructions. The quality and concentration of RNA were determined using a NanoDrop 2000 spectrophotometer, and $1 \mu \mathrm{g}$ of RNA was reverse-transcribed into cDNA following the instructions. The PCR primer sequences are shown in Table I. The amplification conditions were pre-denaturation at $95^{\circ} \mathrm{C}$ for $5 \mathrm{~min}$, and then 40 cycles of denaturation at $95^{\circ} \mathrm{C}$ for $15 \mathrm{~s}$ before annealing/extension at $60^{\circ} \mathrm{C}$ for $60 \mathrm{~s}$, and finally cooling down to $40^{\circ} \mathrm{C}$. Gene expression was calculated through the $2^{-\Delta \Delta c t}$ method. Three duplicate wells were set for each group, and the experiment was repeated three times to obtain an average.

\section{Western blot analysis}

After thorough disruption of the tissues and cells, a proper amount of protein lysis buffer was added to the wells, which were incubated for $20 \mathrm{~min}$ and centrifuged at $1200 \mathrm{rpm}$ for $6 \mathrm{~min}$ (radius $=12 \mathrm{~cm}$ ). The supernatant was obtained. The protein concentration was determined by the quinolinic acid method and adjusted by referring to the protein standard. The proteins were then separated on $10 \%$ sodium dodecyl sulphate-polyacrylamide gel, and the protein bands were transferred to a polyvinylidene fluoride membrane. The membrane was blocked with Tris-buffered saline containing $2 \%$ bovine serum albumin for $90 \mathrm{~min}$, incubated with anti-B2R antibody (1:200), antiCCND-1 antibody (1: 1000) or anti-VEGF-A antibody $(1: 1000)$ at $4^{\circ} \mathrm{C}$ overnight. Moreover, the membrane was incubated with horseradish peroxidase-labelled secondary antibody at $37^{\circ} \mathrm{C}$ for $60 \mathrm{~min}$. GAPDH was used as the internal reference. The protein bands were visualised by the enhanced chemiluminescence method. Grey values of each protein band were determined by Image J software. Three duplicates were set for each group.

\section{CCK-8 assay to determine cell proliferation activity}

HTR-8/SVneo cells with a confluence of 70$90 \%$ were harvested with trypsin containing EDTA and resuspended with RPMI 1640 medium to $10^{5}$ cells $/ \mathrm{ml}$. The suspension was then seeded on a 96-well plate at $100 \mu \mathrm{l} /$ well. After complete adherence, the cells were treated as specified for each group, and $10 \mu \mathrm{l}$ of CCK- 8 reagent was added $24 \mathrm{~h}$ later. The plate was gently shaken to ensure even distribution of the agent in the culture medium and then cultured for $4 \mathrm{~h}$ at $37^{\circ} \mathrm{C}$. Absorbance at a wavelength of $450 \mathrm{~nm}$ was measured using a microplate reader. Three duplicate wells were set for each group, and the experiment was repeated three times to obtain an average.

\section{Flow cytometry to determine cell apoptosis}

The HTR-8/SVneo cells were treated for $72 \mathrm{~h}$ as specified for each group before digestion with trypsin without EDTA. The cells were rinsed with PBS $(2 \mathrm{ml})$ three times and centrifuged to collect the cells at $1200 \mathrm{rpm}$ for $10 \mathrm{~min}$ (radius $=12 \mathrm{~cm}$ ). The cell precipitate was resuspended with $250 \mu \mathrm{l}$ of PBS into single cells before $750 \mu$ of pre-chilled pure ethanol was added to the cells while shaking. The cells were then fixed at $4^{\circ} \mathrm{C}$ overnight. The cells were stained with a dye mix containing RNase, propidium iodide and Triton for $15 \mathrm{~min}$ at $4^{\circ} \mathrm{C}$. Cell apoptosis was determined by flow cytometry. Three duplicate wells were set for each group, and the experiment was repeated three times to obtain an average.

\section{Flow cytometry to determine cell cycle distribution}

After treatment as specified for each group for $72 \mathrm{~h}$, the cells were digested with trypsin without EDTA, washed with PBS three times and centrifuged at $1500 \mathrm{rpm}$ for $5 \mathrm{~min}$ (radius $=12 \mathrm{~cm}$ ). The cell precipitate was resuspended with $250 \mu \mathrm{l}$ of PBS into single cells, and $750 \mu \mathrm{L}$ of pre-chilled pure ethanol was added to the cells while shaking. The cells were fixed at $4^{\circ} \mathrm{C}$ overnight. The

Table I. Primer sequence of difference genes

\begin{tabular}{|lccc|}
\hline Gene & Direction & Primer sequence & Length [bp] \\
\hline miR-29b-3p & $\mathrm{F}$ & TGCGG TAGCACCATTTGAAAT & 20 \\
\cline { 2 - 4 } & $\mathrm{R}$ & CCAGTGCAGGGTCCGAGGT & 19 \\
\hline B2R & $\mathrm{F}$ & GAGGCCAAGCCCTGGTATG & 19 \\
\cline { 2 - 4 } & $\mathrm{R}$ & CGGGCCGATTGATCTCAGC & 19 \\
\hline$\beta$-actin & $\mathrm{F}$ & AAGTCCCTCACCCTCCCAAAAG & 22 \\
& $\mathrm{R}$ & AAGCAATGCTGTCACCTTCCC & 21 \\
\hline
\end{tabular}


cells were then stained with a dye mix containing RNase, propidium iodide and Triton for $15 \mathrm{~min}$ at $4^{\circ} \mathrm{C}$. Cell cycle distribution of the cells was determined by flow cytometry. Three duplicate wells were set for each group, and the experiment was repeated three times to obtain an average.

\section{Cell migration assay}

Cells were seeded in 6-well plates until reaching a confluence of $70-90 \%$. The cells were treated as specified for each group for $6 \mathrm{~h}$, and a straight line was drawn at the centre of each well with a $1 \mathrm{ml}$ pipette tip vertical to the cell plane to ensure that the width of the lines was even. The wells were rinsed with PBS three times, and RPMI 1640 medium containing $10 \%$ FBS was added. The cells were cultured at $37^{\circ} \mathrm{C}$ in a $5 \% \mathrm{CO}_{2}$ incubator for another $48 \mathrm{~h}$, and the sites were photographed again and compared with those at $\mathrm{Oh}$. Three duplicate wells were set for each group, and the experiment was repeated three times to obtain an average.

\section{Cell invasion assay}

The membrane of each transwell chamber $(8 \mu \mathrm{m}$ pore size) was immersed in $50 \mu \mathrm{l}$ of Matrigel diluted with serum-free RPMI-1640 medium and allowed to undergo full polymerisation in a $37^{\circ} \mathrm{C}$ incubator containing 5\% $\mathrm{CO}_{2}$ for 30-60 min. Subsequently, the residual liquid was removed. After $24 \mathrm{~h}$ of treatment, the cells were digested with $0.25 \%$ trypsin, centrifuged after terminating digestion, washed twice with PBS and resuspended in RPMI 1640 medium containing $1 \%$ FBS to $5 \times 10^{5}$ cells $/ \mathrm{ml}$. We added $200 \mu$ l of suspension to the upper chamber of each transwell apparatus, and added the RPMI 1640 containing 10\% FBS to the lower chamber. The chamber was gently assembled to avoid air bubbles and then incubated for $24 \mathrm{~h}$. The transwell chamber was removed, and the Matrigel and cells on the upper side of the membrane were gently wiped off with a wet cotton swab. The chamber was then fixed in $4 \%$ paraformaldehyde for $20 \mathrm{~min}$ at room temperature, stained with $0.2 \%$ crystal violet for $20 \mathrm{~min}$, washed three times with PBS, dried and placed under a microscope. Three $200 \times$ views were randomly selected for each chamber, and the number of cells on the bottom of the membrane was counted.

\section{Immunofluorescence assay to determine $\mathrm{B} 2 \mathrm{R}$ protein expression}

After treatment as specified for each group for $24 \mathrm{~h}$, the cells were cultured in 24-well plates with a cover slip in each plate. After adherence, the cells were treated with $1 \%, 5 \%$ or $10 \%$ FBS for $48 \mathrm{~h}$, washed with PBS two times for $5 \mathrm{~min}$, and fixed with $4 \%$ paraformaldehyde for another $15 \mathrm{~min}$. The cells were washed with PBS again two times for 5 min, penetrated with $0.1 \%$ Triton for $5 \mathrm{~min}$, blocked with $100 \mu \mathrm{l}$ of goat serum for $15 \mathrm{~min}$, incubated with $60 \mu \mathrm{l}$ of anti-B2R antibody ( $1: 75)$ at $4^{\circ} \mathrm{C}$ overnight and incubated with fluorescent secondary antibody $(1: 100)$ at room temperature for 30 min. Finally, the cover slip was sealed with anti-quenching resin containing DAPI and observed under a fluorescence microscope. Photographs were obtained, and B2R expression was compared among the groups.

\section{Statistical analysis}

The data were analysed using SPSS 20.0 software. Data were represented as the mean \pm standard deviation (mean \pm SD). All cell experiments were independently repeated three times. Experimental data were compared among the groups using one-way ANOVA. Pairwise comparison between groups was carried out by LSD analysis for those with equal variance or Dunnett's T3 analysis for those with unequal variance. $P<0.05$ was considered statistically significant.

\section{Results}

\section{Clinical sample analysis}

Figure $1 \mathrm{~A}$ is the HE staining result of a normal placenta sample, which showed well-developed placental villi and uniform matrix. The cells were in good shape with minimal interstitium. The tissue was well vascularised, and the nuclei of the syncytiotrophoblasts were neatly arranged. A few red blood cells were observed in the lumen of the villus capillary, and cellulose-like necrosis was noted around the villi. The placental tissue of patients with PE was undeveloped. The villi were poorly vascularised with interstitial oedema, and nuclei of the syncytiotrophoblasts were deranged. More cellulose-like necrosis was observed around the villi, with decreased blood vessels and narrowed lumen. These alterations were more remarkable in patients with severe PE than in mild cases. miR-29b-3p and B2R mRNA of each group were determined by RT-PCR, which showed higher miR-29b-3p PE than that in normal controls ( $p<$ 0.001 ; Figure $1 \mathrm{~B}$ ). By contrast, B2R expression in patients with PE was significantly decreased (Figure 1 C). miR-29b-3p and B2R also mRNA showed a dramatic difference between patients with severe and mild PE ( $p<0.05$; Figures $1 \mathrm{~B}$ and $\mathrm{C}$ ).

\section{Effect of miR-29b-3p inhibitor on expression of miR-29b-3p and B2R in each group}

As revealed by RT-PCR, miR-29b-3p in both the model and miR-NC groups significantly increased, compared with the NC group ( $p<0.001$; Figure 2 A), 
A
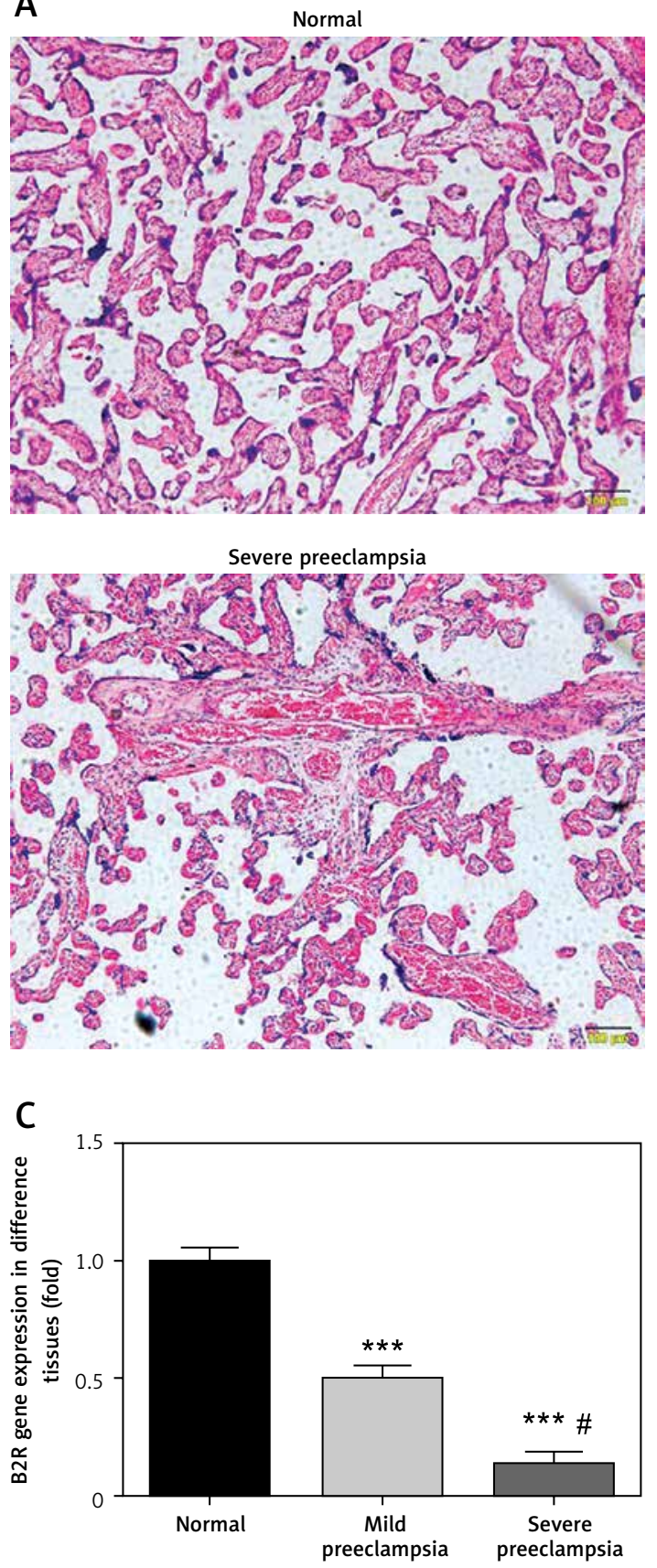

whereas B2R expression significantly decreased $(p<0.001$; Figure 2 B). miR-29b-3p inhibitor significantly decreased miR-29b-3p expression compared with the model group $(p<0.001$; Figure $2 \mathrm{~A})$ and increased B2R expression ( $p<0.001$; Figure 2 B). This result indicated that the miR-29b-3p inhibitor exerted a significant inhibitory effect on miR-29b$3 p$, which could effectively inhibit B2R expression.

\section{Effect of miR-29b-3p inhibitor on proliferation and apoptosis}

To identify the effect of miR-29b-3p inhibitor on the cell proliferation of the HTR-8/SVneo
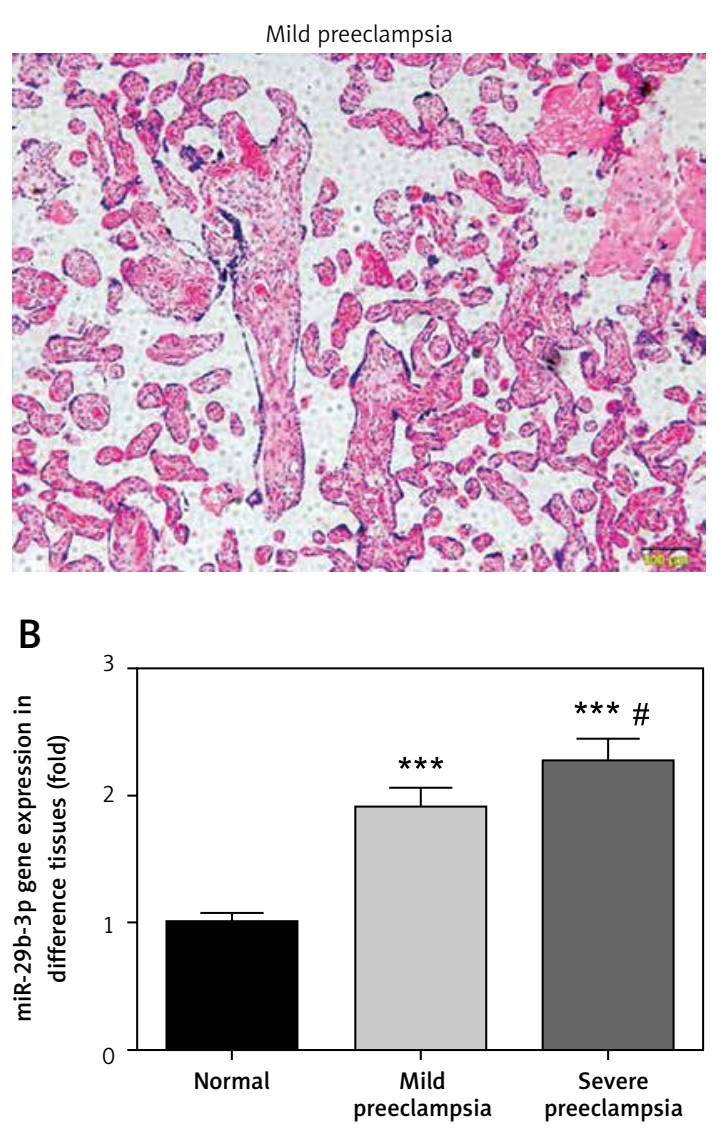

Figure 1. Clinical sample analysis. A - Pathology of differencetissues byHEstaining (100x). B-miR-29b$3 p$ mRNA expression by RT-qPCR in different tissues. C - B2R mRNA expression by RT-qPCR in different groups

${ }^{* * *} p<0.001$ compared with normal tissues, ${ }^{*} p<0.05$ compared with mild preeclampsia.

cells, the proliferation rate of the cells was detected by CCK-8 assay. We measured apoptosis and cell cycle by flow cytometry. The model and miR-NC groups showed significantly decreased cell proliferation compared with the NC group $(p<0.001$; Figure $3 \mathrm{~A})$ and significantly increased apoptosis and G1 distribution ( $p<0.001$; Figures $3 \mathrm{~B}$ and $\mathrm{C}$ ). Meanwhile, compared with the model group, the miR-29b-3p inhibitor group showed significantly increased cell proliferation $(p<0.001$; Figure 3 A) but significantly decreased apoptosis and G1 retention $(p<0.001$; Figures $3 \mathrm{~B}$ and $\mathrm{C}$ ). Relevant data are shown in Figure 3. 
A

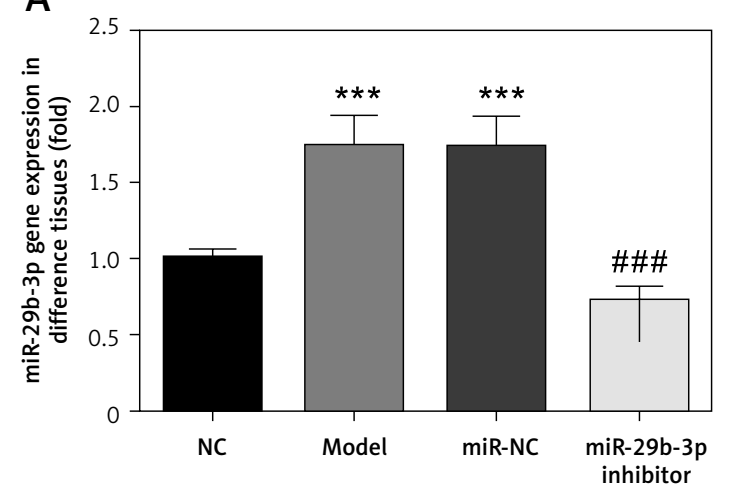

B

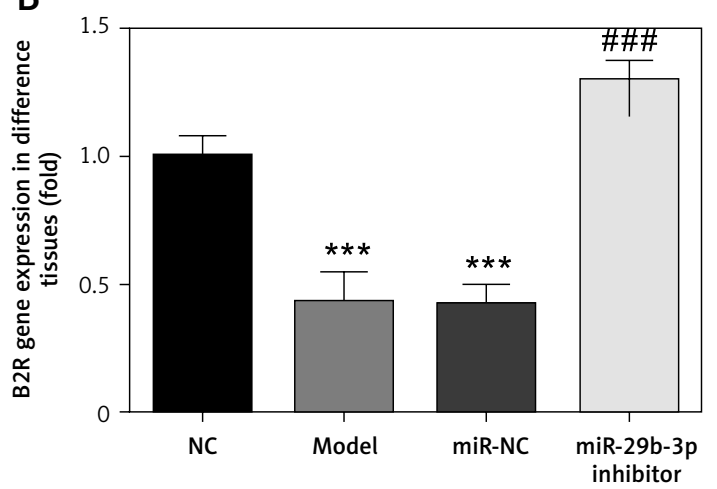

Figure 2. Relative mRNA expression in difference cell groups by RT-qPCR. A - miR-29b-3p mRNA expression by RT-qPCR in different cell groups. B - B2R mRNA expression by RT-qPCR in different cell groups

${ }^{* * *} p<0.001$ compared with NC group, ${ }^{\# \# \#} p<0.001$ compared with Model group.

\section{Effect of miR-29b-3p inhibitor on invasion and migration of cells in each group}

To show the effect of the miR-29b-3p inhibitor on the invasion and migration of the cells, the number of invading cells was determined via transwell assay. Compared with the NC group, the model and miR-NC groups showed significantly decreased numbers of invading cells $(p<0.001$; Figure 4 A), whereas miR-29b-3p treatment significantly increased cell invasion compared with the model group $(p<0.001$; Figure 4 A). The effect of miR-29b-3p inhibitor on the migration of the HTR-8/SVneo cells was determined by scratch wound healing assay. The model and miR-NC groups showed significantly decreased numbers of migrated cells, compared with the NC group ( $p<$ 0.001; Figure 4 B), whereas miR-29b-3p treatment significantly increased cell migration compared with the model group ( $p<0.001$; Figure 4 B).

\section{Expression of relevant proteins}

The protein expression levels of B2R, VEGF-A, CCND1, MMP-2 and MMP-9 were detected by Western blot assay. Compared with the NC group, the model and miR-NC groups showed significantly decreased B2R, VEGF-A, CCND1, MMP-2 and MMP-9 protein expression $(p<0.001$; Figure 5 A). By contrast, treatment with miR-29b-3p inhibitor significantly increased the expression of these proteins compared with the model group $(p<0.001$; Figure 5 A). B2R protein expression in the cells was also determined by immunofluorescence staining. Compared with the NC group, the model and miR-NC groups showed significantly decreased B2R protein expression $(p<0.001$; Figure $5 \mathrm{~B}$ ), whereas treatment with miR-29b$3 p$ inhibitor significantly increased B2R protein expression compared with the model group $(p<$ 0.001 ; Figure 5 B). Relevant data are shown in Figure 5.

\section{$B 2 R$ overexpression affects relative mRNA expression}

Unlike the NC group, miR-29b-3p mRNA expression significantly increased in the model, pCDNA3.1 and pcDNA3.1-B2R groups $(p<0.001$; Figure $6 \mathrm{~A}$ ), and B2R mRNA expression significantly decreased in the model and pcDNA-3.1 groups $(p<0.001$; Figure 6 B). Moreover, pcDNA 3.1-B2R transfection significantly increased B2R mRNA level, which was different from the control group $(p<0.001$; Figure 6 B).

\section{Effect of B2R on cell proliferation, apoptosis and cell cycle distribution}

Compared with the NC group, the model and pcDNA 3.1 groups showed significantly inhibited cell proliferation $(p<0.001$; Figure 7 A), significantly increased apoptosis $(p<0.001$; Figure 7 B) and significant $\mathrm{G} 1$ retention ( $p<0.001$; Figure $7 \mathrm{C}$ ). By contrast, pcDNA-3.1-B2R transfection significantly promoted cell proliferation $(p<0.001$; Figure 7 A), decreased apoptosis $(p<0.001$; Figure 7 B) and released cell cycle retention $(p<0.001$; Figure 7 C).

\section{Effect of B2R on cell invasion and migration}

Unlikely the NC group, the number of invading cells significantly decreased in the model and pcDNA 3.1 groups $(p<0.001$; Figure $8 A$ ) but increased after pcDNA 3.1-B2R transfection $(p<0.001$; Figure 8 A). Wound healing assay also demonstrated that the wound healing rate of the model and pcDNA 3.1 groups was dramatically lower than that of the NC group ( $p<0.001$; Figure 8 B).

\section{Expression of B2R and relevant proteins}

By Western blot, the protein expression of B2R, VEGF-A, CCND1, MMP-2 and MMP-9 significantly decreased in the model and pcDNA 3.1 groups, 


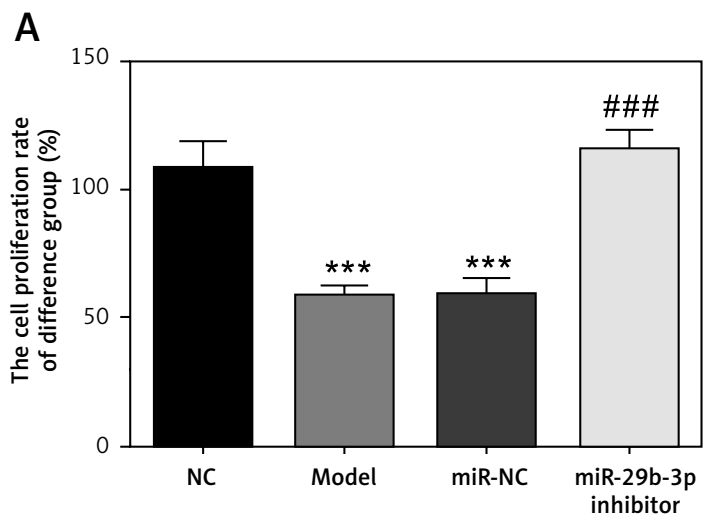

B
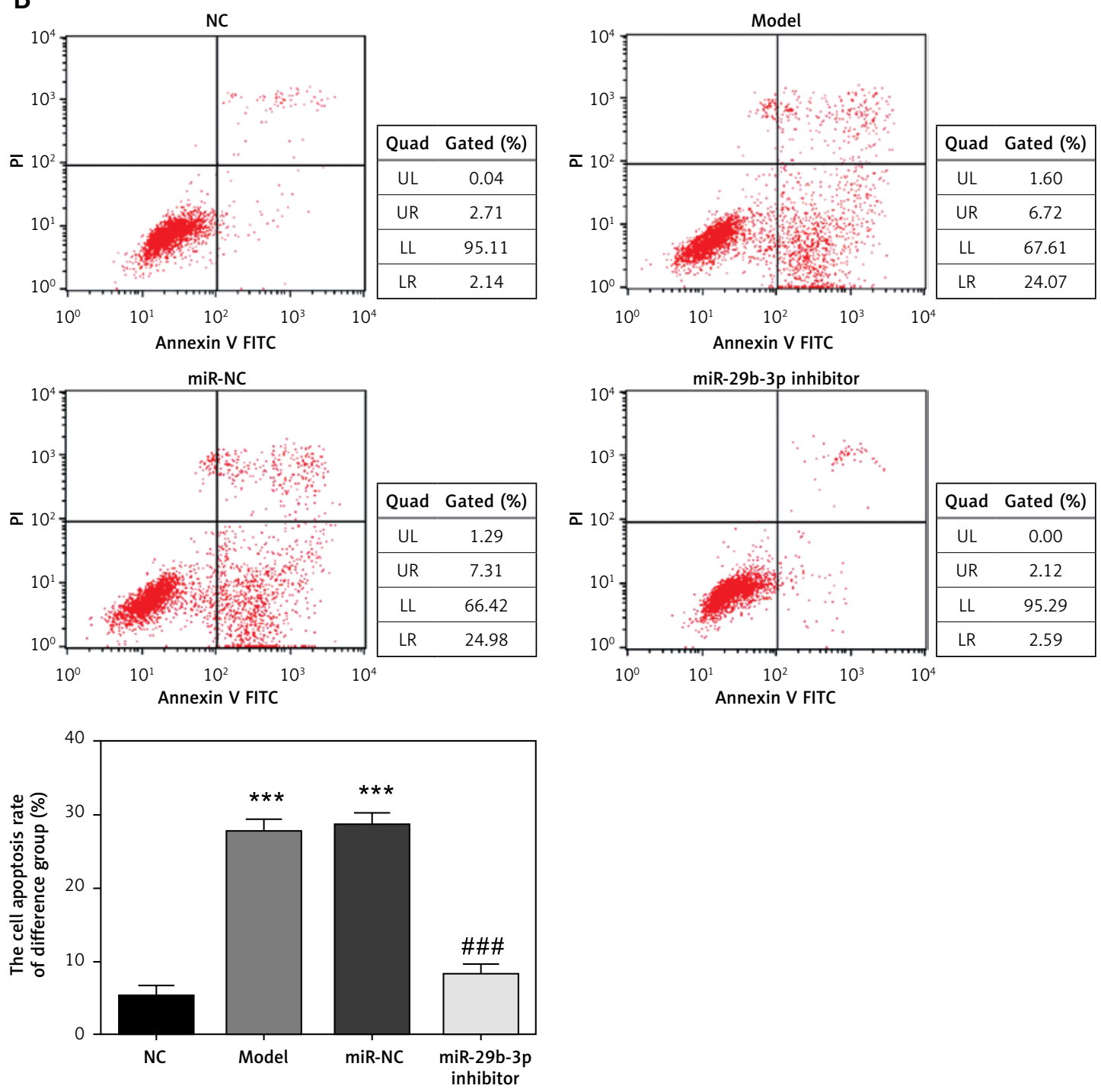

Figure 3. miR-29b-3p inhibitor affects cell proliferation, apoptosis and cell cycle. A - miR-29b-3p inhibitor affects cell proliferation by CCK-8, B - miR-29b-3p inhibitor affects cell proliferation by flow cytometry

${ }^{* * *} p<0.001$ compared with NC group, ${ }^{* \# *} p<0.001$ compared with Model group. 
C

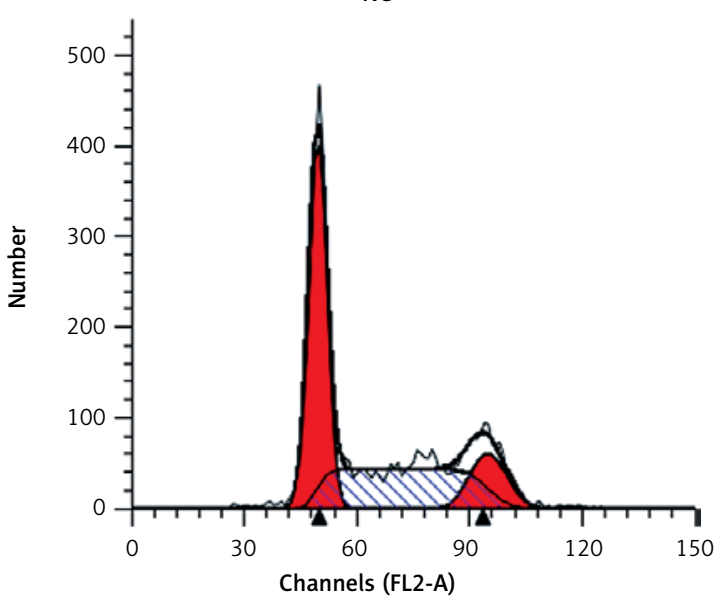

miR-NC
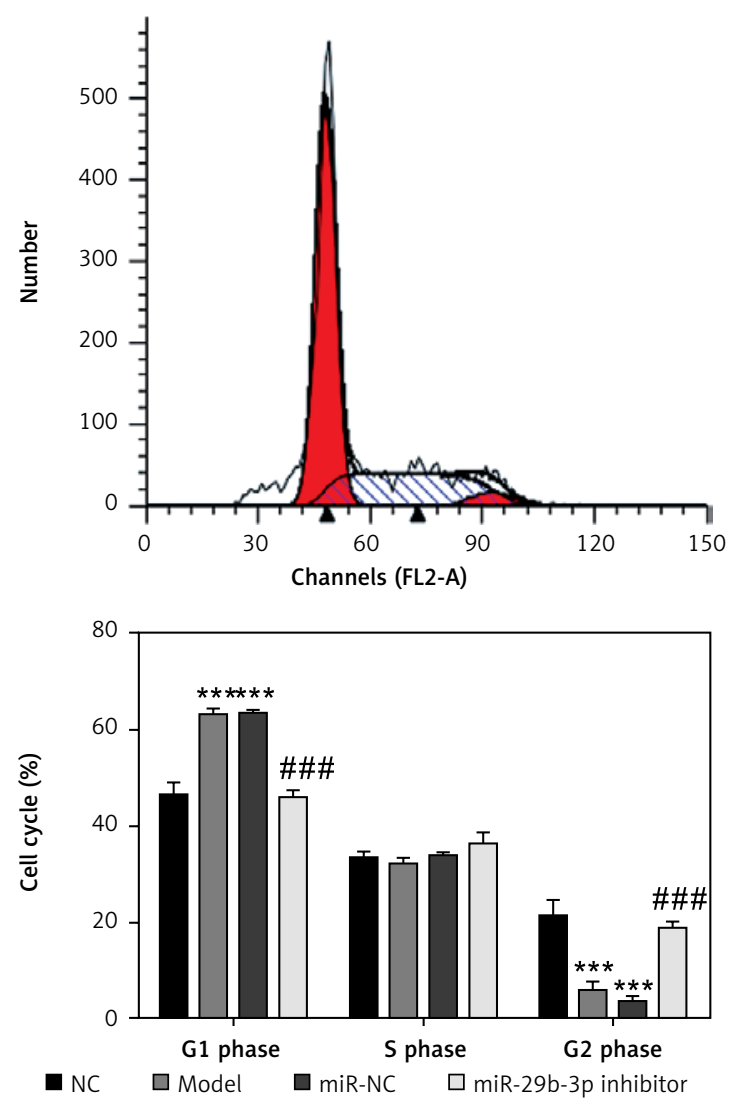

compared with the NC group $(p<0.001$; Figure 9 A). By contrast, treatment with pcDNA 3.1$B 2 R$ significantly increased the expression of these proteins compared with the model group $(p<0.001$; Figure 9 A). Immunofluorescence staining demonstrated significantly decreased $B 2 R$ protein expression in the model and pcDNA 3.1 groups compared with the NC group $(p<0.001$; Figure 2 B), whereas pcDNA 3.1-B2R transfection significantly increased $B 2 R$ expression compared with the model group $(p<0.001$; Figure 9 B).
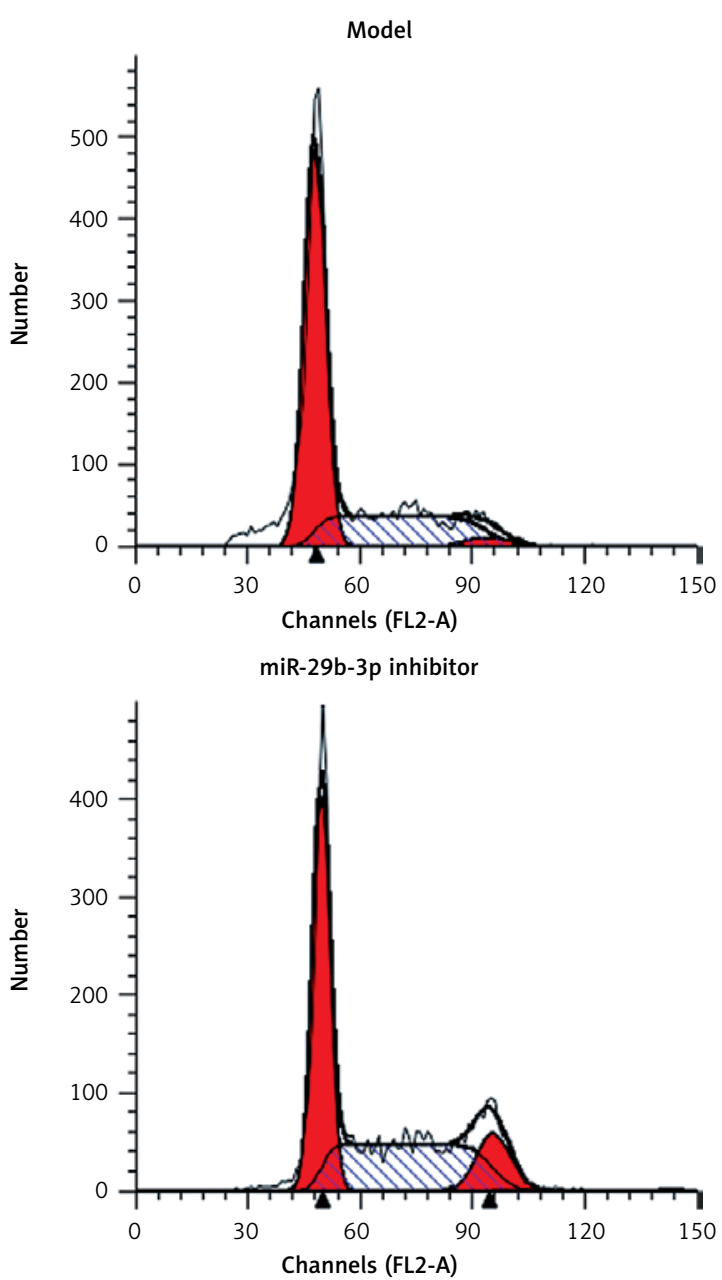

Figure 3. Cont. C - miR-29b-3p inhibitor affects cell cycle by flow cytometry

Effect of miR-29b-3p inhibitor and/or pcDNA 3.1-siB2R on miRNA expression of relevant genes

MiR-29b-3p and B2R expression of the model group differed significantly from those in the NC group ( $p<0.001$; Figures $10 \mathrm{~A}$ and $\mathrm{B})$. In particular, miR-29b-3p inhibitor treatment dramatically decreased miR-29b-3p expression $p<0.001$; Figure $10 \mathrm{~A})$ and increased B2R expression $(p<0.001$; Figure 10 B). Treatment with pcDNA 3.1-siB2R in addition to miR-29b-3p inhibitor significantly de- 

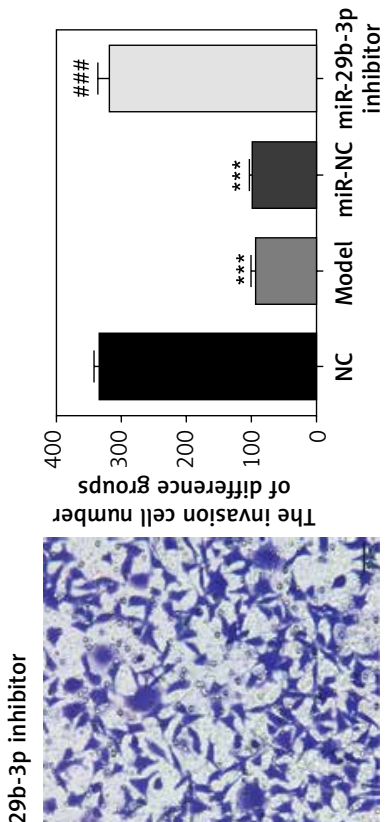

i

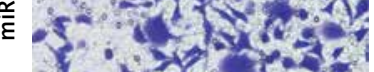

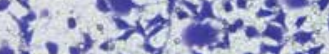
a.
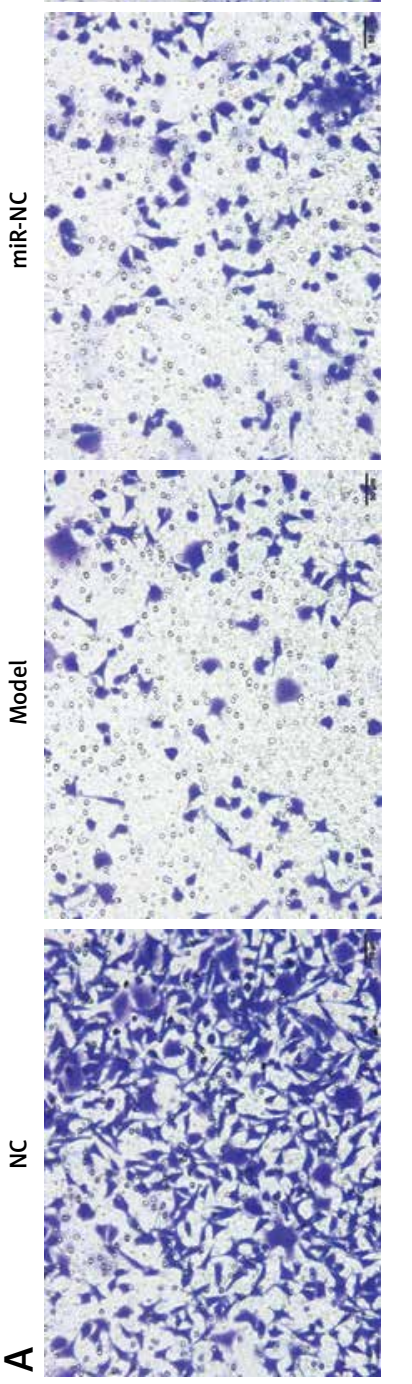

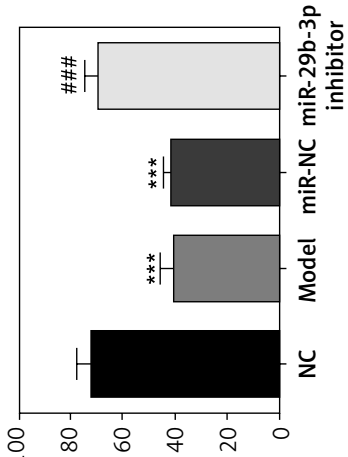

(\%) sdnoı8 әзиәләң!p јо әред 8и!ןеәч punom
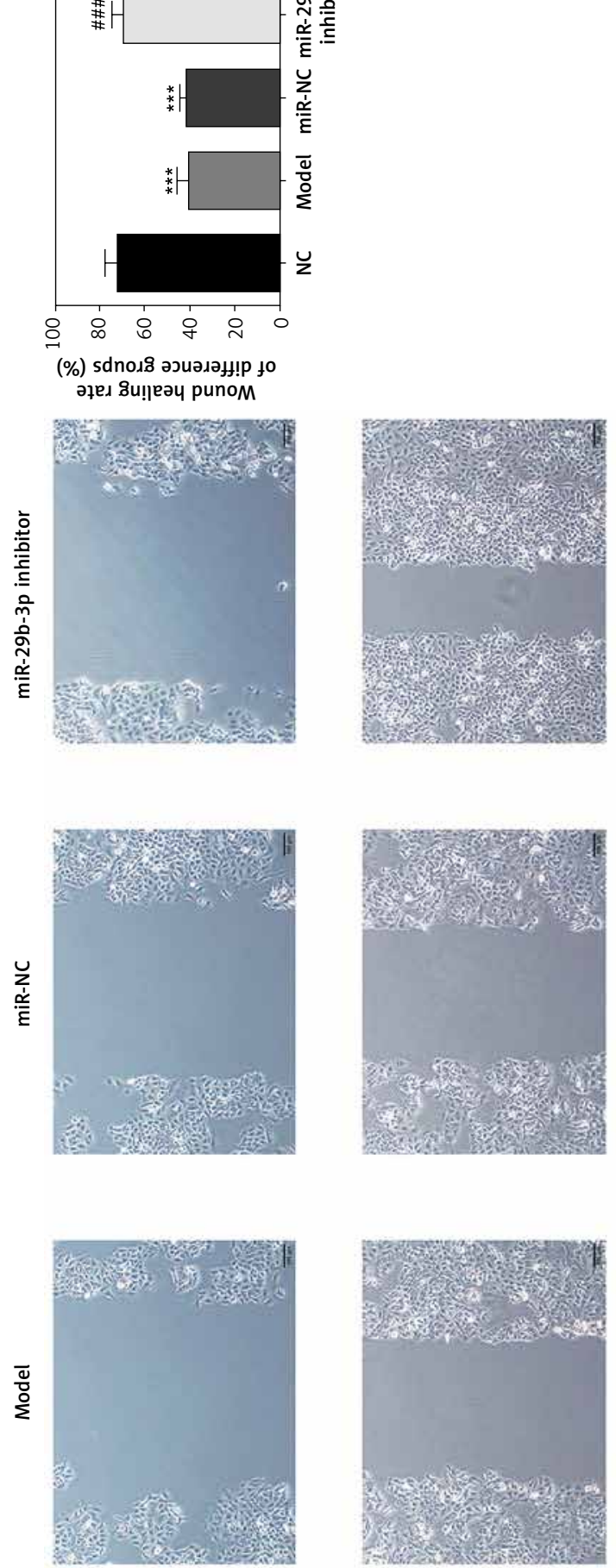

$\breve{z}$

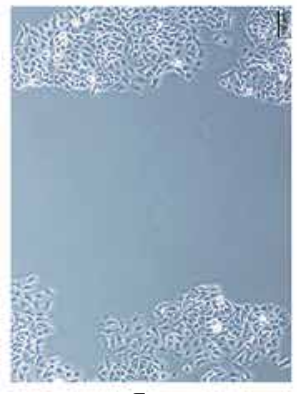

ร 

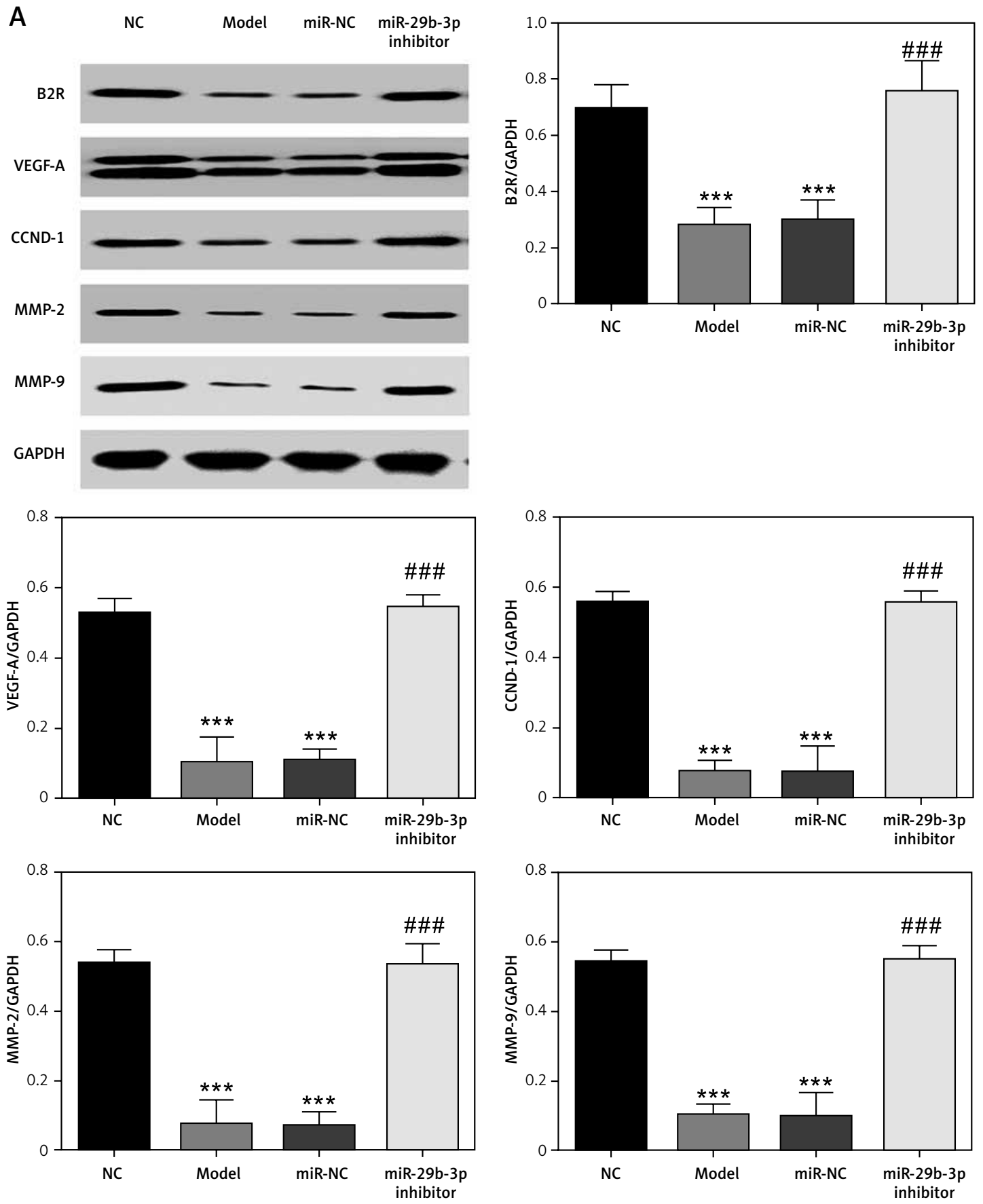

Figure 5. Relative protein expression in different groups. A - Relative protein expression by WB assay

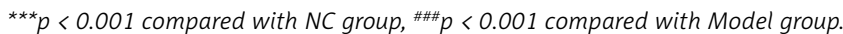



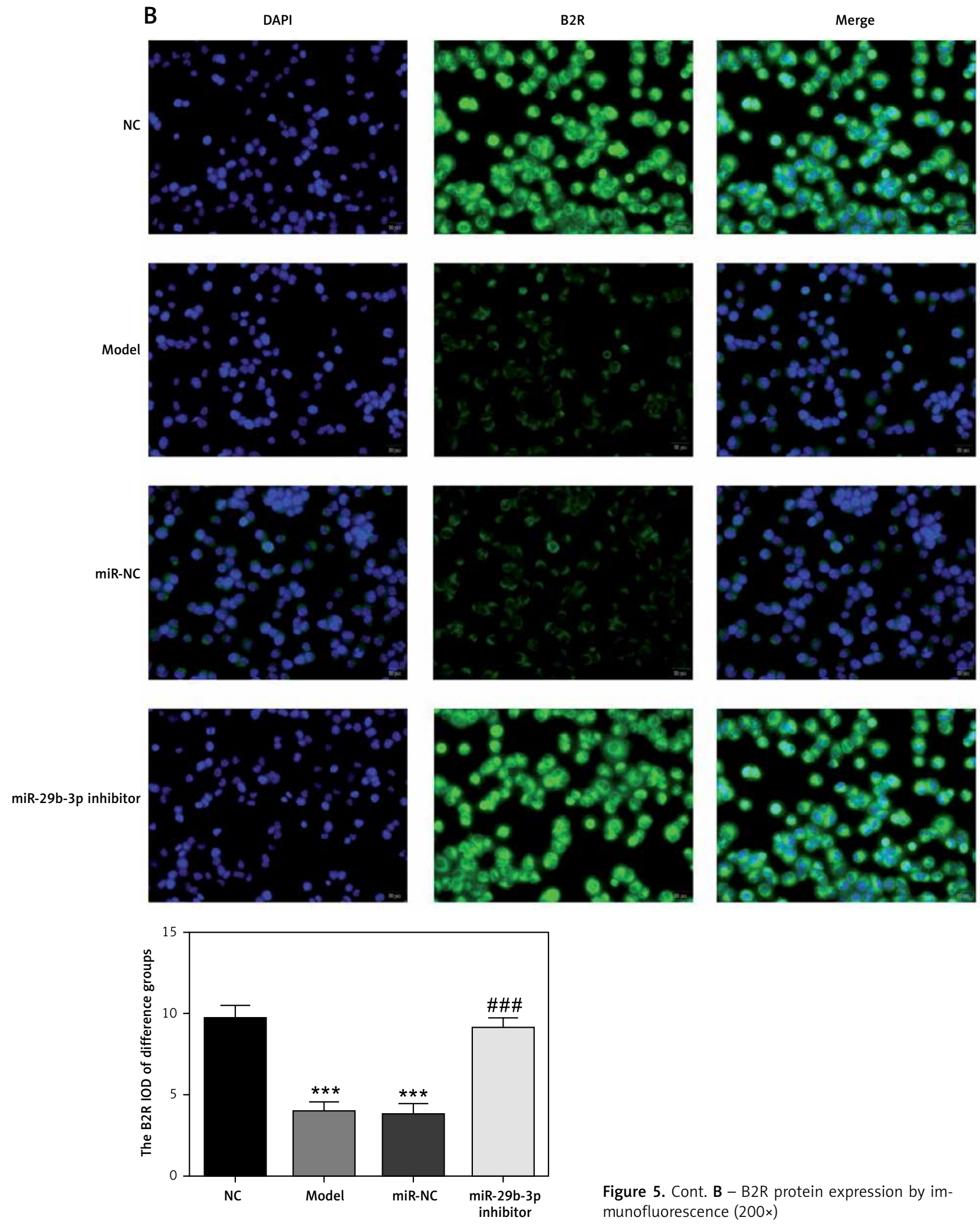

Figure 5. Cont. B - B2R protein expression by immunofluorescence (200x) 
A

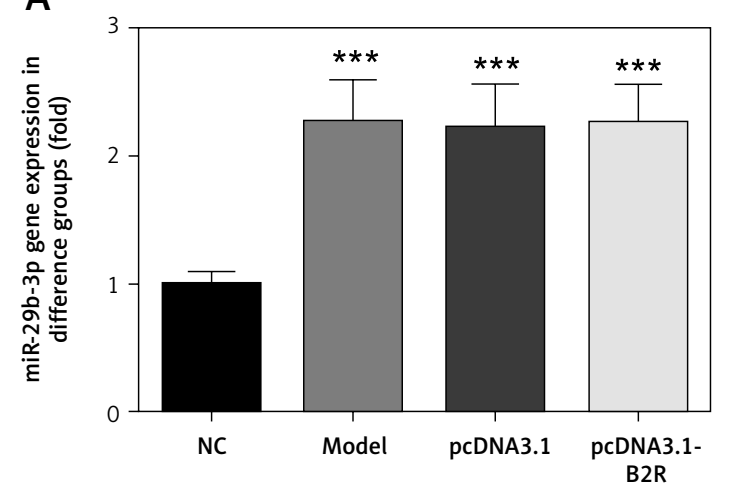

B

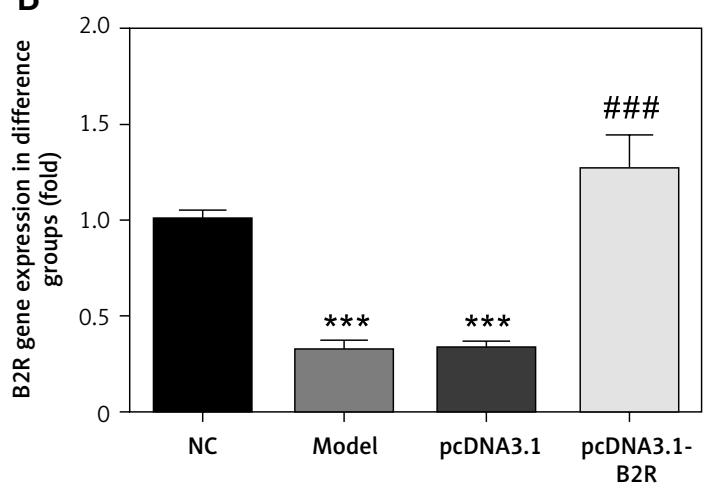

Figure 6. B2R up-regulation affects relative mRNA expression by RT-qPCR. A - miR-29b-3p mRNA expression by RT-qPCR assay, $\mathbf{B}-\mathrm{B} 2 \mathrm{R}$ gene expression by RT-qPCR assay

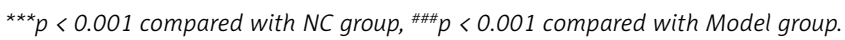

creased B2R mRNA expression compared with the miR-29b-3p inhibitor group.

\section{Effects of miR-29b-3p inhibitor and/or pcDNA 3.1-siB2R on cell proliferation, apoptosis and cell cycle}

Unlike the NC group, the model group showed significantly decreased cell proliferation $(p<0.001$; Figure $11 \mathrm{~A}$ ), increased apoptosis and elevated $\mathrm{G} 1$ retention ( $p<0.001$; Figures 11 B and C). Treatment with the miR-29b-3p inhibitor increased cell proliferation, inhibited apoptosis and alleviated $\mathrm{G} 1$ retention compared with the model group ( $p<0.001$; Figures $11 \mathrm{~A}-\mathrm{C}$ ). By contrast, treatment with pcDNA 3.1-siB2R in addition to miR-29b-3p inhibitor significantly decreased cell proliferation, increased apoptosis and enhanced $\mathrm{G} 1$ retention ( $p<0.001$; Figures $11 \mathrm{~A}-\mathrm{C})$.

\section{Effect of miR-29b-3p inhibitor and/or pcDNA 3.1-siB2R on cell invasion and migration}

Transwell assay showed a significant reduction in invading cells in the model group, compared with the NC group ( $p<0.001$; Figure $12 \mathrm{~A})$. The miR-29b$3 p$ inhibitor significantly increased cell invasion compared with the model group $(p<0.001$; Figure 12 A). Treatment with pcDNA 3.1-siB2R in addition to miR-29b-3p inhibitor significantly inhibited cell invasion compared with the miR-29b-3p inhibitor group ( $p<0.001$; Figure $12 \mathrm{~A})$. Wound healing assay showed similar results. Wound healing was significantly inhibited in the model group compared with that in the NC group ( $p<0.001$; Figure $12 \mathrm{~B})$. The miR-29b-3p inhibitor significantly increased cell migration compared with the model group $(p<0.001$; Figure $12 \mathrm{~B}$ ), whereas treatment with pcDNA 3.1siB2R in addition to miR-29b-3p inhibitor significantly inhibited cell migration compared with the miR-29b-3p inhibitor group ( $p<0.001$; Figure 12 B).
Effect of miR-29b-3p inhibitor and/or pcDNA 3.1-siB2R on protein expression of relevant genes

Western blot showed significantly decreased protein expression of B2R, VEGF-A, CCND1, MMP-2 and MMP-9 in the model group compared with the NC group ( $p<0.001$; Figure 13 A). The miR-29b$3 p$ inhibitor significantly increased the expression of these proteins compared with the model group ( $p<0.001$; Figure $13 \mathrm{~A}$ ), whereas treatment with pcDNA 3.1-siB2R in addition to miR-29b-3p inhibitor significantly inhibited the expression of these proteins compared with the miR-29b-3p inhibitor group ( $p<0.001$; Figure $13 \mathrm{~A}$ ). Immunofluorescence staining showed significantly decreased B2R expression in the model group compared with the NC group ( $p<0.001$; Figure $13 \mathrm{~B}$ ). The miR-29b-3p inhibitor significantly increased B2R expression compared with the model group ( $p<0.001$; Figure $13 \mathrm{~B}$ ), whereas treatment with pcDNA 3.1-siB2R in addition to miR-29b-3p inhibitor significantly inhibited B2R expression compared with the miR-29b-3p inhibitor group ( $p<$ 0.001 ; Figure $13 \mathrm{~B}$ ).

\section{Discussion}

Preeclampsia is an idiopathic disease that causes significantly increased morbidity and mortality of pregnant women and perinatal infants, yet its pathogenesis remains unclear $[8,9]$. Normal extravillous trophoblasts' biological activities (proliferation, migration and invasion) are the key factors for remodelling of uterine spiral arteries. During the formation of the placenta, extravillous trophoblasts invade into the basal aponeurosis and the superficial myometrium of the uterus, replacing the endothelial cells on the vascular wall of the uterine spiral artery and remodelling the uterine spiral artery [10]. Preeclampsia is a pregnancy-related disease caused by trophoblast dys- 


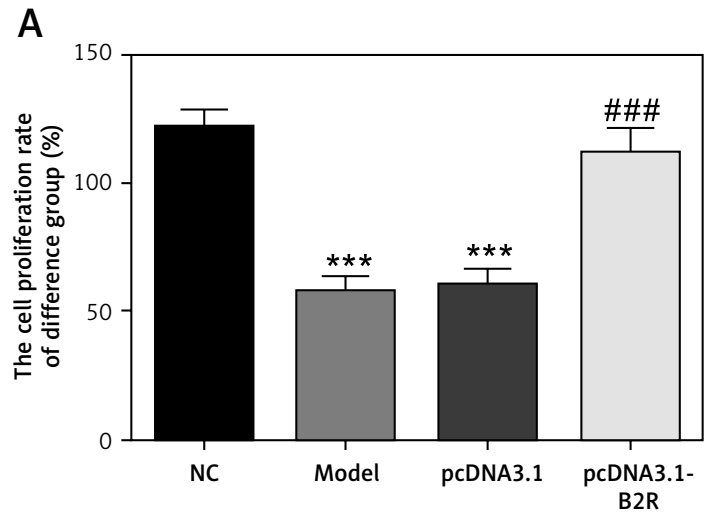

B
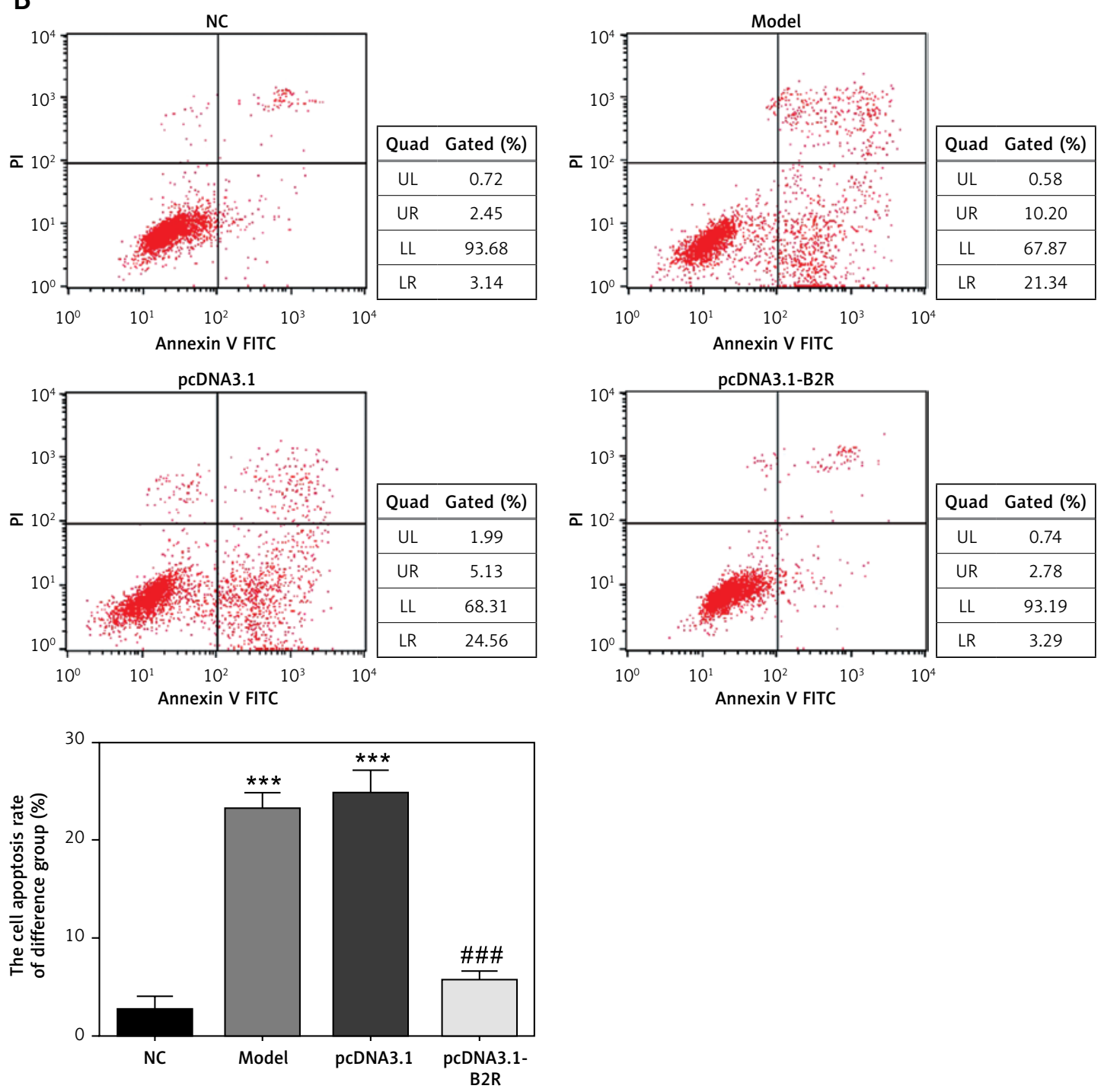

Figure 7. B2R affects cell proliferation, apoptosis and cell cycle in different groups. A - B2R affects cell proliferation by CCK-8 assay, B - B2R affects cell apoptosis by flow cytometry

${ }^{* * *} p<0.001$ compared with NC group, \#\#\#p $<0.001$ compared with Model group. 
C

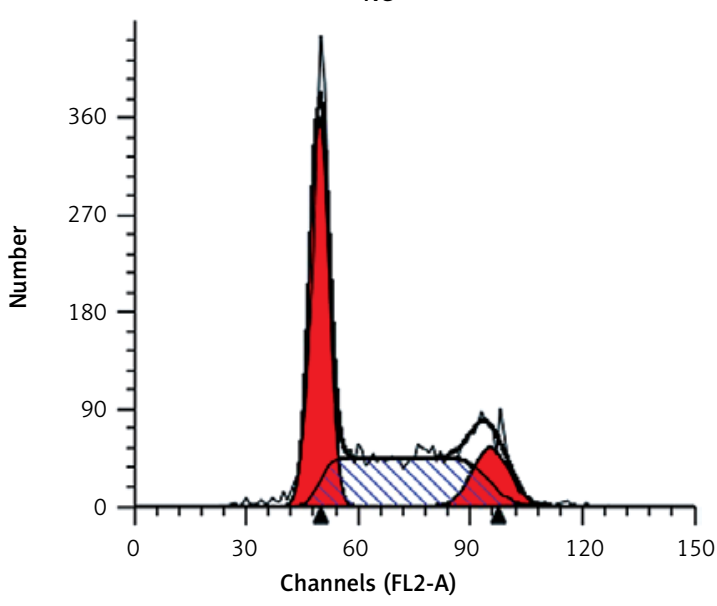

pcDNA3.1
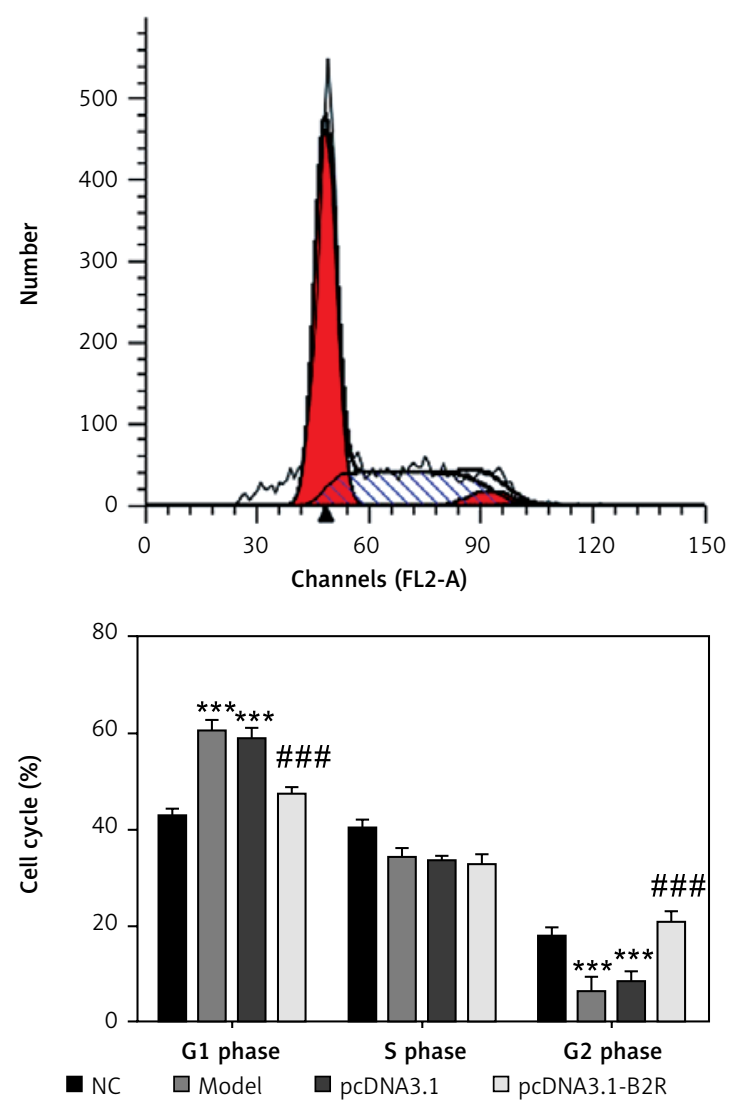

function [11]. Relative studies have reported that miRNAs played a significant part in the occurrence of PE; they may affect the invasiveness of trophoblasts by regulating expression of downstream target genes [12, 13]. MiR-29b-3p played a key role in tumours' occurrence and development, but its expression and function during PE have not been clarified; moreover, the correlation between miR-29b-3p and B2R has rarely been reported $[13,14]$. DNA microarray gene screening revealed a significant reduction in B2R expression in early villus tissue in patients with PE [15], suggesting that B2R may be involved in trophoblast function.
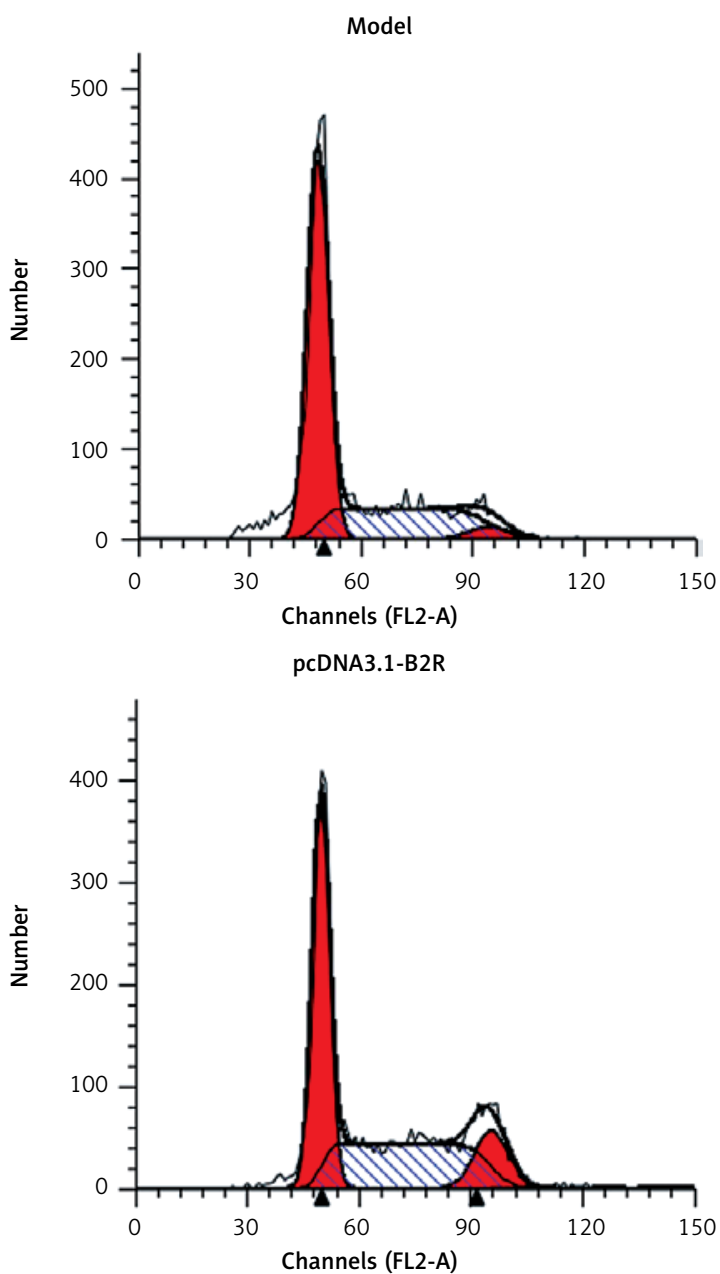

Figure 7. Cont. C - B2R affects cell cycle by flow cytometry

This study firstly evaluated miR-29b-3p and B2R expression levels in normal, mild and severe PE placenta and then explored their association with $B 2 R$ and role in eclampsia by in vitro cell experiments.

In this study, we used CCK-8 and flow cytometry to determine the effects of miR-29b-3p and B2R on trophoblastic proliferation and cell cycle progression. These results also identified that miR-29b-3p downregulation or B2R overexpression improved the proliferation of HTR-8/SVneo cells and cell cycle progression from G1 phase to $S$ phase. Meanwhile, treatment with siB2R sup- 


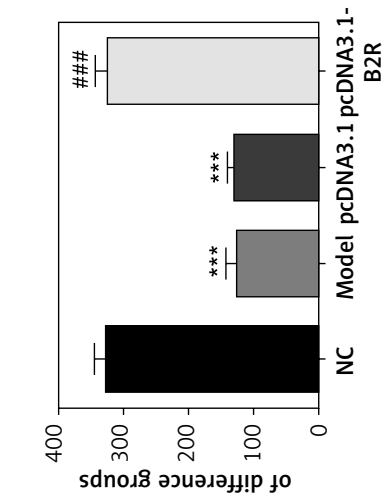

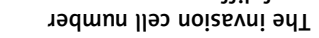
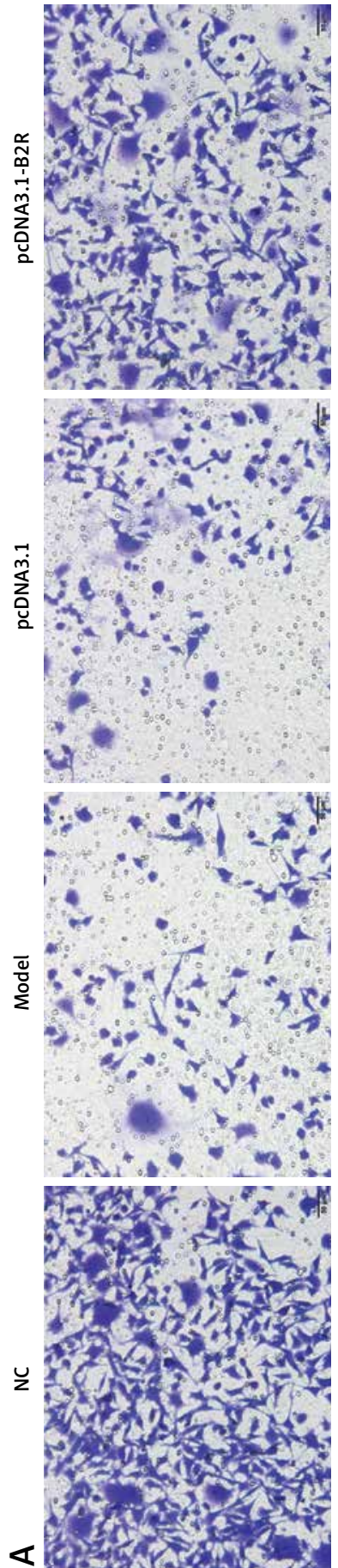
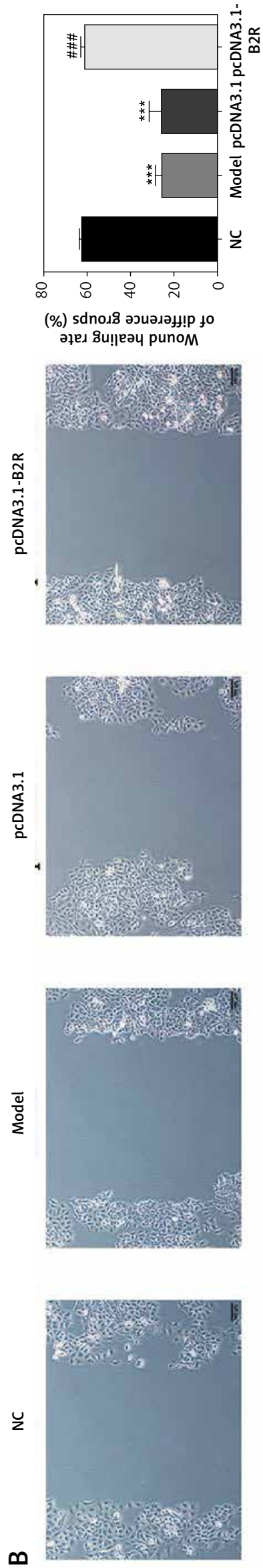

ร

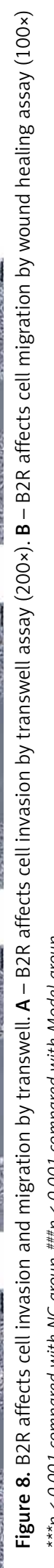

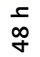



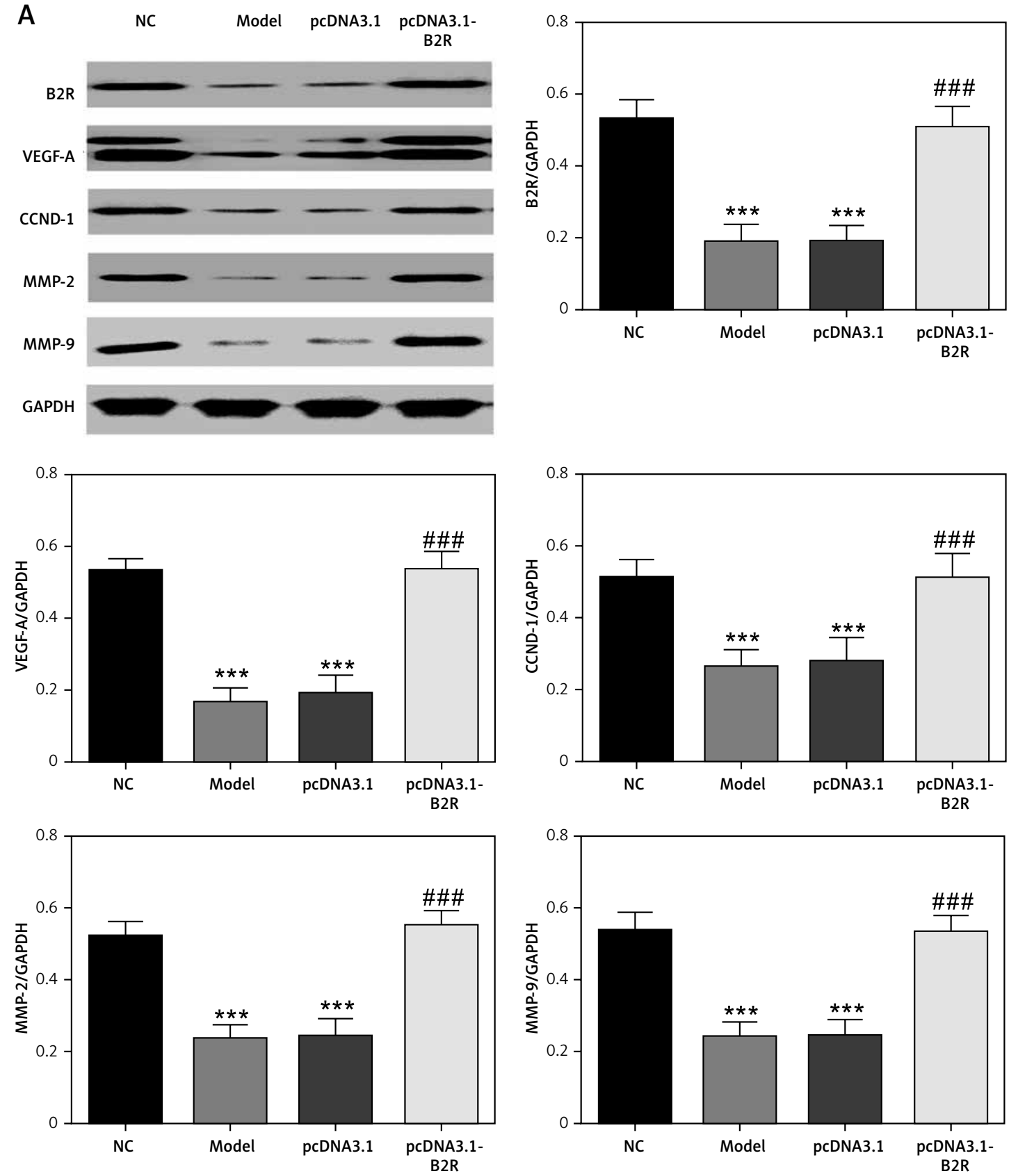

Figure 9. Relative protein expression in different groups. A - Relative protein expression by WB assay ${ }^{* * *} p<0.001$ compared with NC group, ${ }^{\# \# *} p<0.001$ compared with Model group. 

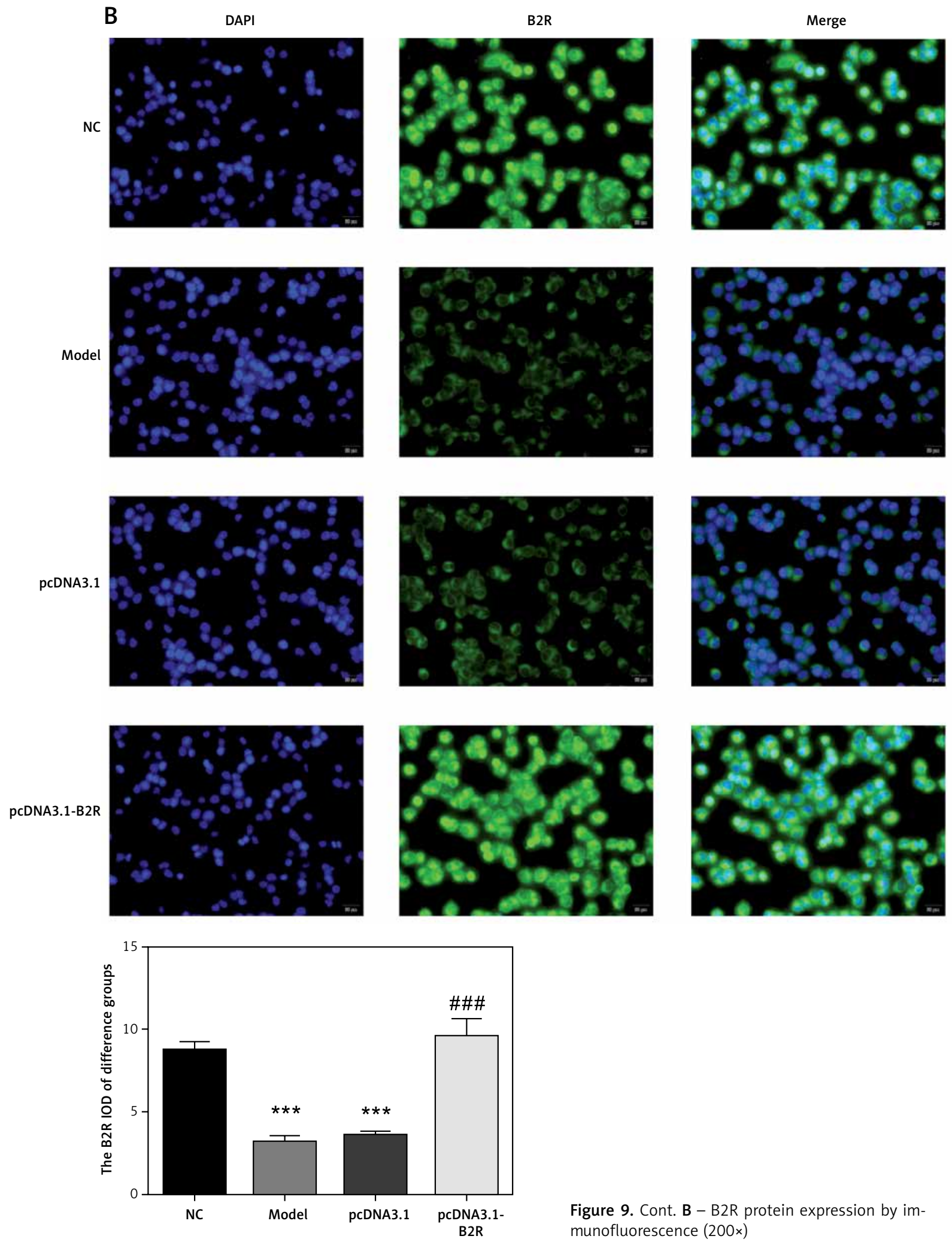

Figure 9. Cont. B - B2R protein expression by immunofluorescence (200x) 
A

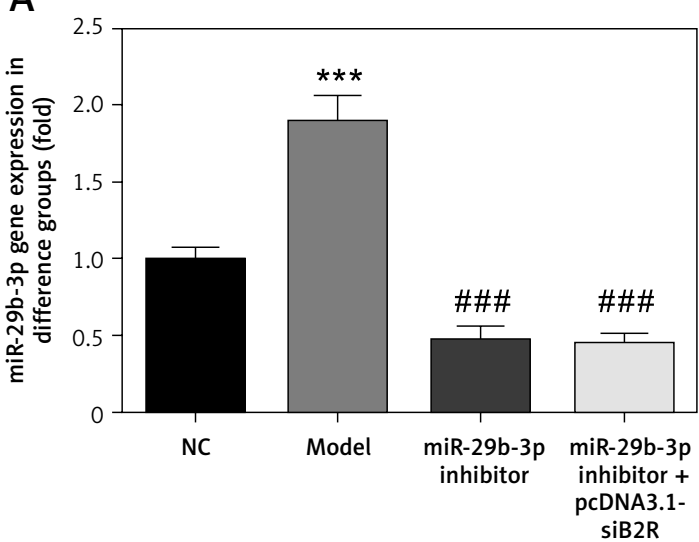

B

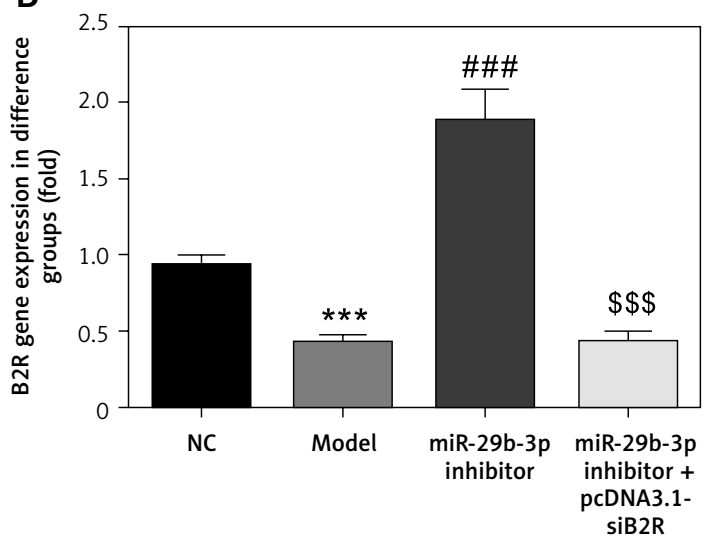

Figure 10. miR-29b-3p inhibitor and/or pcDNA 3.1-siB2R affects relative mRNA expression. A - miR-29b-3p mRNA expression in different groups by RT-qPCR, B - B2R mRNA expression in different groups by RT-qPCR

${ }^{* * *} p<0.001$ compared with NC group, ${ }^{\# \#} p<0.001$ compared with Model group, ${ }^{\$ S s} p<0.001$ compared with miR-29b-3p inhibitor group.

pressed HTR-8/SVneo cell proliferation and kept the cell cycle in the G1 phase.

Extravillous trophoblasts show active migration, invasion and ring formation, which are important in placental formation and uterine spiral arterial remodelling. Therefore, this study also explored the effect of miR-29b-3p and B2R on the migration of HTR-8/SVneo cells. By cell migration and invasion assays, the results showed that miR-29b-3p inhibitor or B2R supplement significantly promoted migration and invasion compared with those of the model group in HTR-8/SVneo cells. By contrast, transfecting siB2R in addition to miR-29b-3p inhibitor significantly inhibited HTR-8/SVneo cell migration and invasion compared with the miR-29b-3p inhibitor group. This study also examined molecules associated with cell migration and invasion, such as MMP-2 and MMP-9 [4]. The results showed that MMP-2 and MMP-9 in HTR-8/SVneo cells transfected with miR-29b-3p inhibitor or B2R-expressing plasmid significantly increased compared with those in the model group. In conclusion, high expression of $\mathrm{B} 2 \mathrm{R}$ or miR-29b-3p inhibitor promoted the proliferation, invasion and migration of HTR-8/SVneo cells, whereas B2R reduction had the opposite effect. Our results also suggested that $B 2 R$ may be a target of miR-29b-3p.

$B 2 R$ is a bradykinin receptor that participates in many cellular functions primarily through activation of downstream signalling pathways in conjunction with bradykinin. In vascular endothelial cells, B2R in conjunction with bradykinin promotes the synthesis of nitric oxide, which relaxes blood vessels and increases vascular permeability, thereby promoting the formation of new blood vessels [16]. In tumour cells, B2R in conjunction with bradykinin promotes interleukin- 6 expression, thereby inducing cell migration and invasion. In vitro cell migration assays and invasion assays also suggested that bradykinin promotes cell migration and invasion by activating B2R to increase pseudopods of extravillous trophoblasts $[17,18]$. The results of this study suggested that miR-29b-3p inhibitor or B2R may directly activate downstream signalling pathways or mediate endogenous bradykinin or other ligands to promote trophoblast function. Previous studies have shown that receptors can function without corresponding ligands; for example, oestrogen receptors may promote the migration and invasion of ovarian cancer cell lines OVCA 420 and ES-2 independently of oestrogen $[19,20]$. Given the complexity of the mechanism, the molecular mechanisms of how changes in B2R expression can influence biological function require further investigation.

The present research also detected the expression of cell cycle-associated CCND-1 and angiogenesis-associated VEGF-A. CCND-1 is a G1/S phase-specific cyclin that activates the E2F response gene by binding to cyclin kinase-4 to promote DNA synthesis, thereby promoting cell proliferation and regulating cell cycle progression [21]. In addition, the down-regulation of CCND-1 expression inhibits the proliferation and migration of human extravillous trophoblasts, suggesting that CCND-1 is also involved in the migration of these cells. VEGF-A is an indispensable molecule for trophoblast survival, proliferation, migration and invasion and promoted extravillous trophoblast migration [22], down-regulating VEGF-A expression and inhibiting extravillous trophoblast invasion [23]. Studies have shown that the expression of CCND-I and VEGF-A in placental tissue is significantly reduced in patients with PE [24, 25]. This study demonstrated that miR-29b-3p inhibitor promoted CCND-1 and VEGF-A protein levels by promoting B2R expression. Thus, increased B2R expression caused by miR-29b-3p 


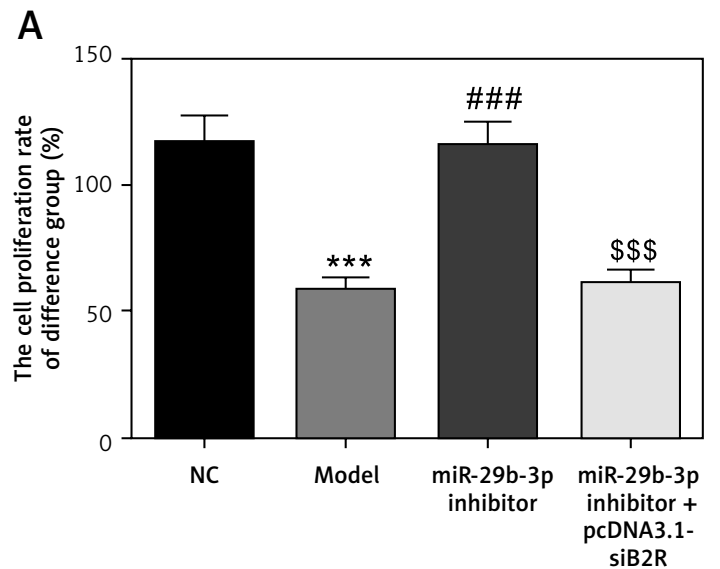

B
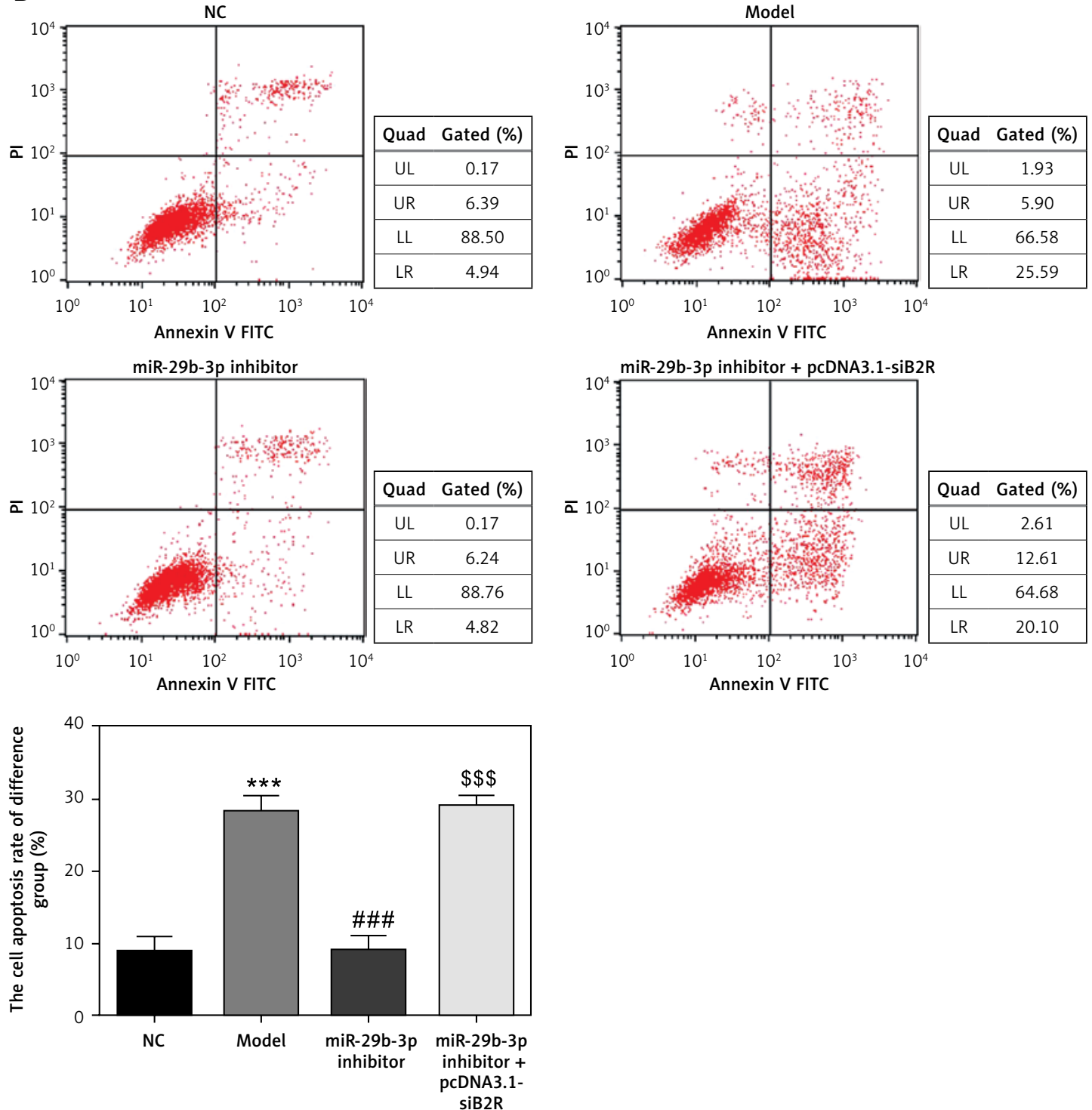

Figure 11. miR-29b-3p inhibitor and/or pcDNA 3.1-siB2R affects cell proliferation, apoptosis and cell cycle. A - miR-29b-3p inhibitor and/or pcDNA 3.1-siB2R affects cell proliferation by CCK-8, B - miR-29b-3p inhibitor and/ or pcDNA 3.1-siB2R affects cell apoptosis by flow cytometry

${ }^{* * *} p<0.001$ compared with NC group, ${ }^{\# \# \# p} p<0.001$ compared with Model group, ${ }^{S S S} p<0.001$ compared with miR-29b-3p inhibitor group. 
C

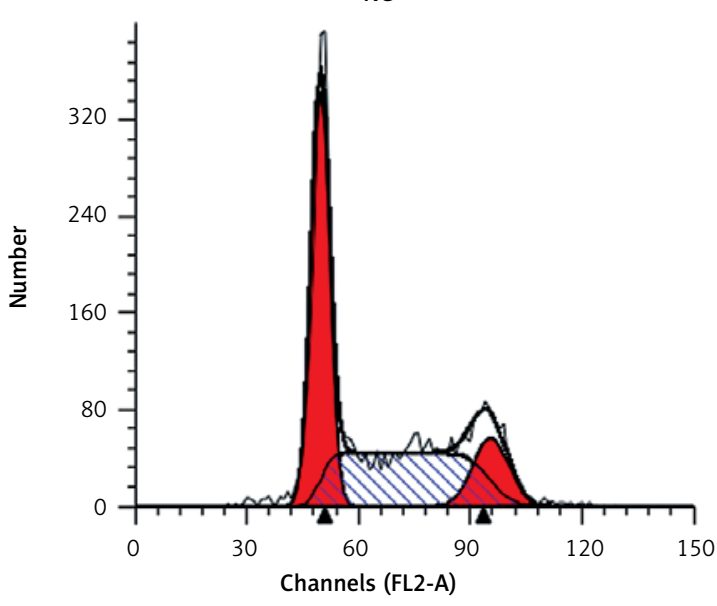

miR-29b-3p inhibitor
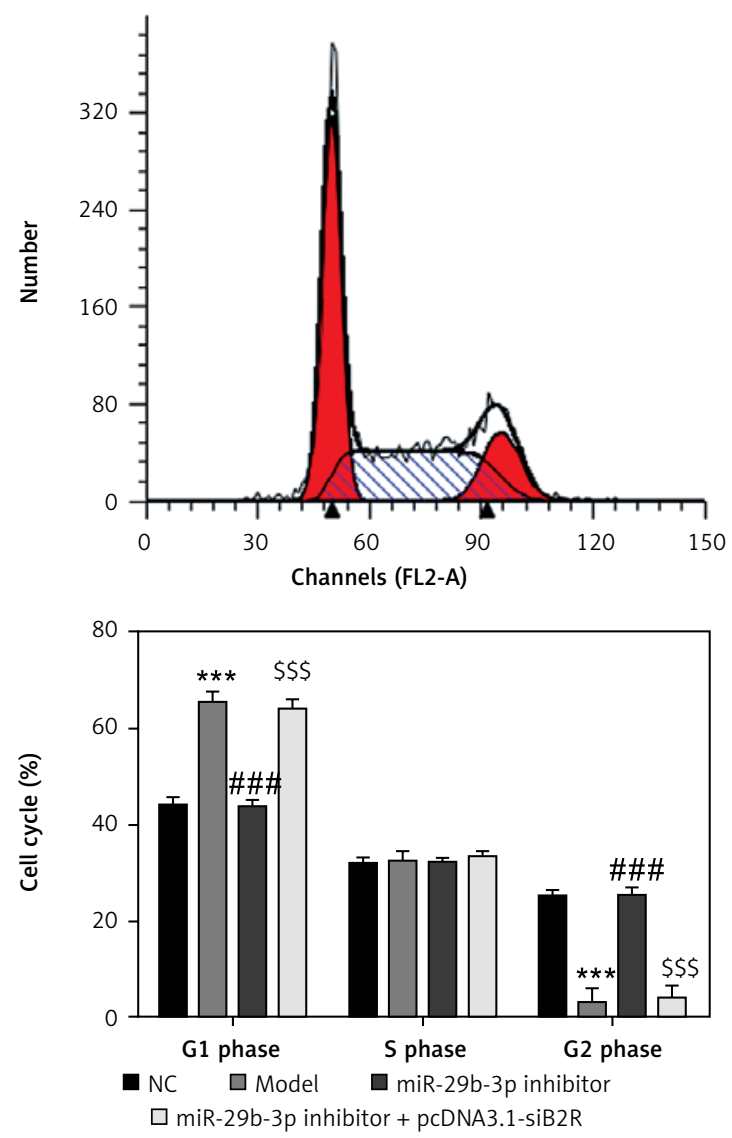

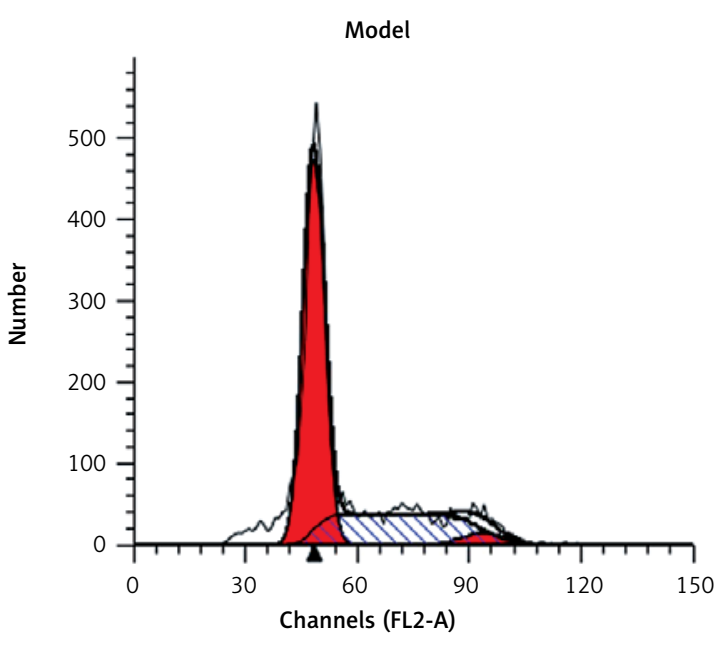

miR-29b-3p inhibitor + pcDNA3.1-siB2R

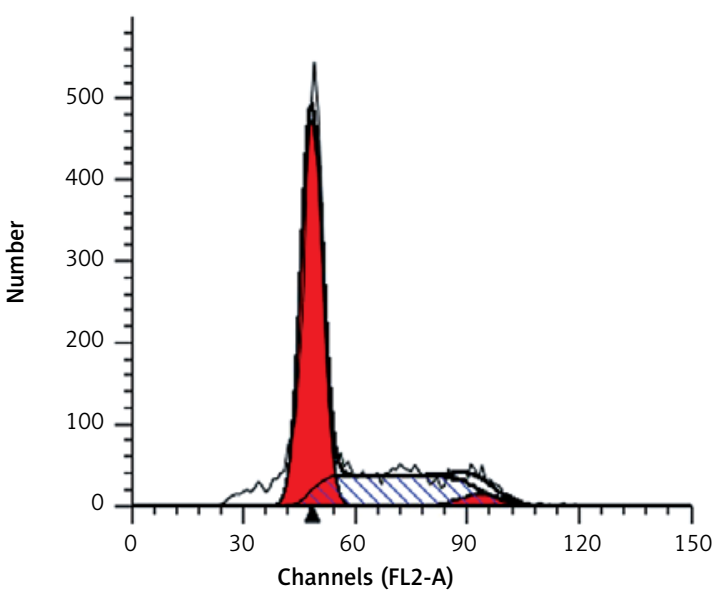

Figure 11. Cont. C - miR-29b-3p inhibitor and/or pcDNA 3.1-siB2R affects cell cycle by flow cytometry 


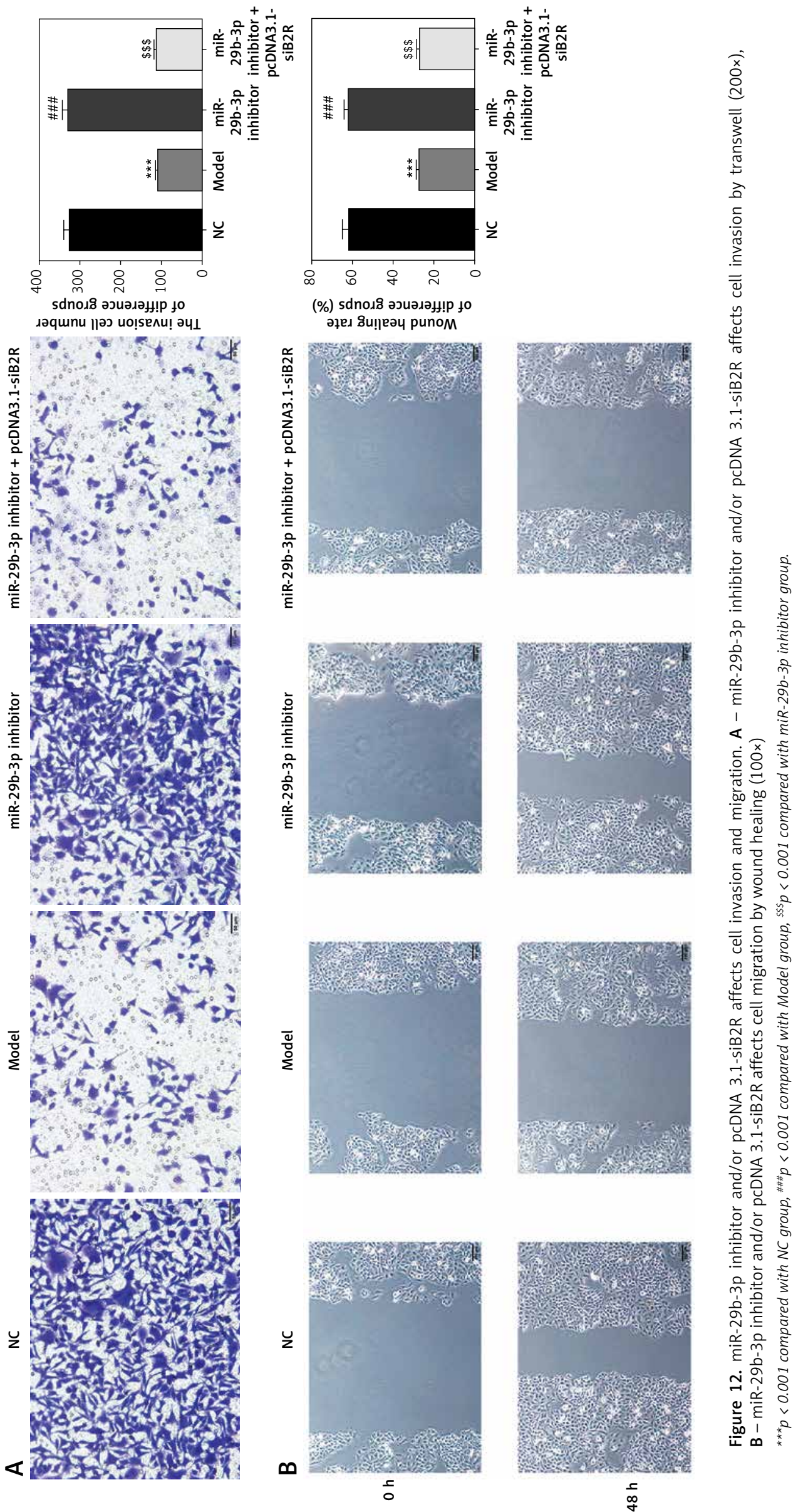



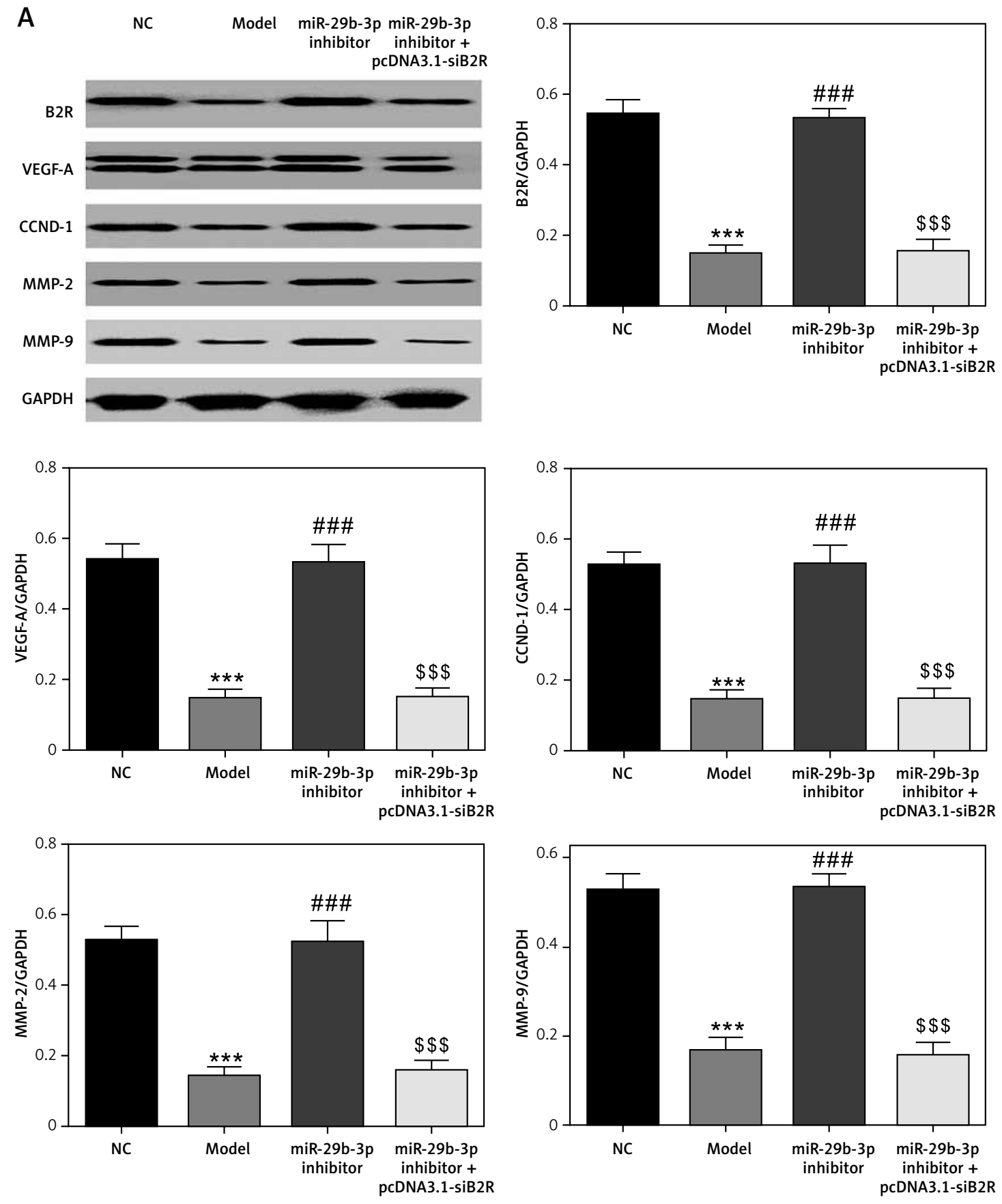

Figure 13. Relative protein expression in different groups. A - Relative protein expression by WB

${ }^{* * *} p<0.001$ compared with NC group, ${ }^{\# \# \#} p<0.001$ compared with Model group, ${ }^{\$ S S} p<0.001$ compared with miR-29b-3p inhibitor group. 

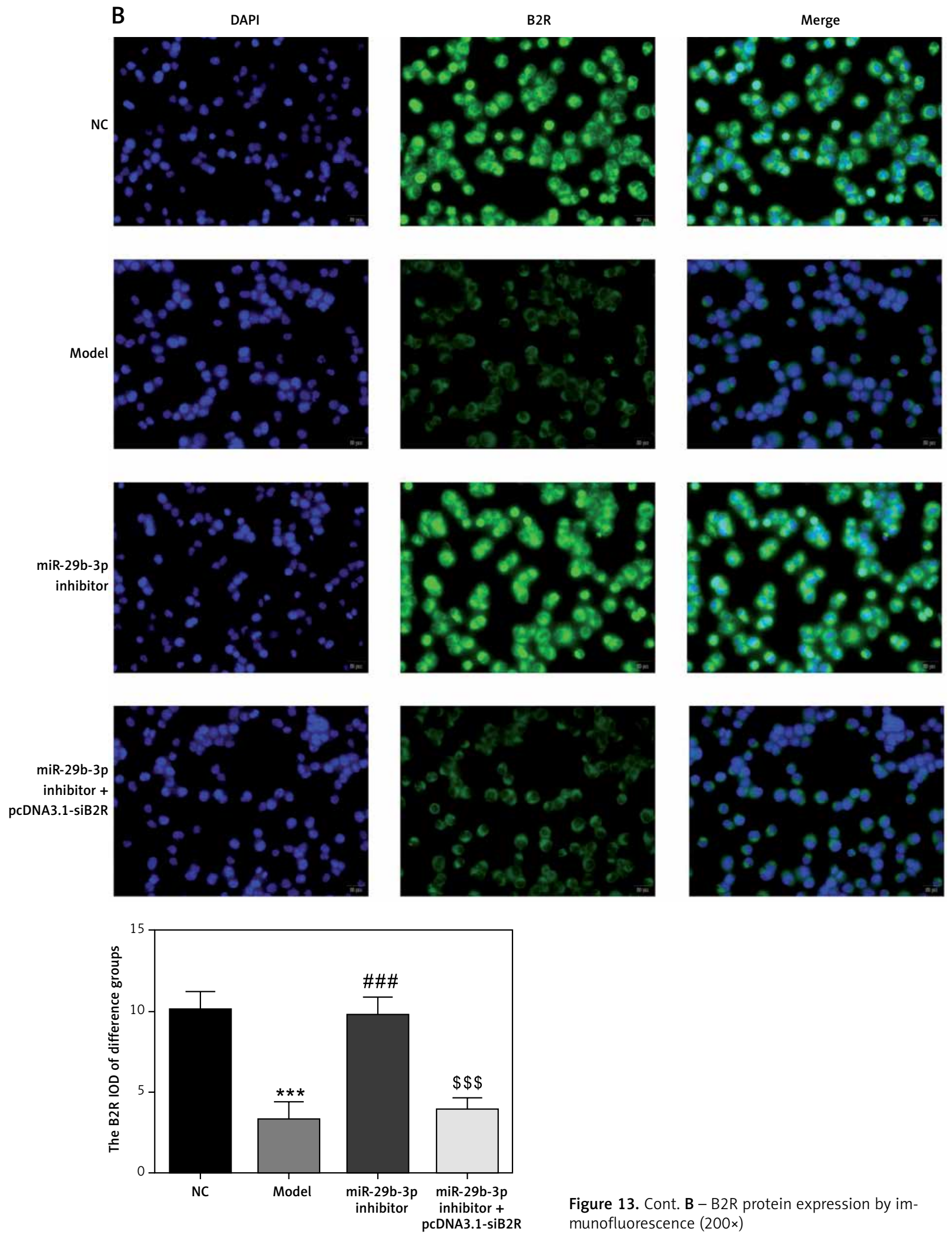

Figure 13. Cont. B - B2R protein expression by immunofluorescence (200x) 
inhibitor may promote trophoblast proliferation and migration/invasion by increasing CCND-1 and VEGF-A expression, respectively.

In conclusion, in extravillous trophoblast HTR-8/ SVneo cells, B2R might be a potential target of miR-29b-3p. miR-29b-3p inhibition could effectively increase B2R expression, thereby promoting the extravillous trophoblasts' biological activities including proliferation, migration and invasion, which are necessary for remodelling of the uterine spiral artery and are associated with many pregnancy complications. However, the specific molecular mechanism remains unclear.

\section{Conflict of interest}

The authors declare no conflict of interest.

\section{References}

1. Red-Horse K, Zhou Y, Genbacev O, et al. Trophoblast differentiation during embryo implantation and formation of the maternal-fetal interface. J Clin Invest 2004; 114 744-54.

2. Kaufmann P, Black S, Huppertz B. Endovascular trophoblast invasion: implications for the pathogenesis of intrauterine growth retardation and preeclampsia. Biol Reprod 2003; 69: 1-7.

3. Duzyj CM, Buhimschi IA, Laky CA, et al. Extravillous trophoblast invasion in placenta accrete is associated with differential local expression of angiogenic and growth factors: a cross-sectional study. BJOG 2018; 125: 1441-8.

4. Zong L, Wei X, Gou W, et al. Zinc improves learning and memory abilities of feral growth restriction rats and promotes trophoblast cell invasion and migration via enhancing STAT3-MMP-2/9 axis activity. Oncotarget 2017; 8: 115190-201.

5. Dai Y, Qiu Z, Diao Z, et al. MicroRNA-155 inhibits proliferation and migration of human extravillous trophoblast derived HTR-8/SVneo cells via down-regulating cyclin D1. Placenta 2012; 33: 824-9.

6. Valdés G, Acuña S, Munizaga A, et al. Utero-placental cellular and nuclear expression of bradykinin B2 receptors in normal and preeclamtic pregnancies. Pregnancy Hypertens 2016; 6: 30-7.

7. Valdes G, Schneider D, Corthorn J, et al. OS059. Blockade of the bradykinin B2 receptor in early pregnancy reduces fetal growthe and trophoblast invasion in guinea-pigs. Pregnancy Hypertens 2012; 2: 208-9.

8. Vaiman D. Genes, epigenetics and miRNA regulation in the placenta. Placenta 2017; 52: 127-33.

9. Buckberry S, Bianco-Miotto T, Bent SJ, et al. Placental transcriptome co-expression analysis reveals conserved regulatory programs across gestation. BMC Genomics 2017; 18: 10

10. Pijnenborg R, Vercruysse L, Hanssens M. The uterine spiral arteries in human pregnancy: facts and controversies. Placenta 2006; 27: 939-58.

11. Zhou Y, Damsky CH, Fisher SJ. Preeclampsia is associated with failure of human cytotrophoblasts to mimic a vascular adhesion phenotype. One cause of defective endovascular invasion in this syndrome? J Clin Invest 1997; 99: 2152-64.
12. Ospina-Prieto S, Chaiwangyen W, Herrmann J, et al. MicroRNA-141 is upregulated in preeclamptic placentae and regulates trophoblast invasion and intercellular communication. Transl Res 2016; 172: 61-72.

13. Sun M, Chen H, Liu J, et al. MicroRNA-34a inhibits human trophoblast cell invasion by targeting MYC. BMC Cell Biol 2015; 16: 21.

14. Wan YQ, Feng JG, Li M, et al. Prefrontal cortex miR-29b$3 p$ plays a key role in the antidepressant-like effect of ketamine in rats. Exp Mol Med 2018; 50: 140.

15. Rabaglino MB, Post Uiterweer ED, Jeyabalan A, et al. Bioinformaties approach reveals evidence for impaired endometrial maturation before and during early pregnancy in women who developed preeclampsia. Hypertension 2015; 65: 421-9.

16. Sheng ZL, Yao YY, Li YF, et al. Transplantation of bradykinin-preconditioned human endothelial progenitor cells improves cardiac function via enhanced Akt/eNOS phosphorylation and angiogenesis. Am J Transl Res 2015; 7: 1214-26.

17. Wang G, Ye Y, Zhang X, et al. Bradykinin stimulates IL-6 production and cell invasion in colorectal cancer cells. Oncol Rep 2014; 32: 1709-14.

18. Erices R, Corthorn J, Lisboa F, et al. Bradykinin promotes migration and invasion of human immortalized trophoblasts. Reprod Biol Endocrinol 2011; 9: 97.

19. Bachelard H, Charest-Morin X, Marceau F. D-Argo-Bradykinin-Arg-Arg, a 1atent vasoactive bradykinin B2 recePto $r$ agoni st metab01iea11Y acti $v$ ated bY carboxypeptidases. Front Pharmacol 2018; 9: 273.

20. Chan KKL, Siu MKY, Jiang YX, et al. Differential expression of estrogen receptor subtypes and variants in ovarian cancer: effects on cell invasion-proliferation and prognosis. BMC Cancer 2017; 17: 606.

21. Musgrove EA, Caldon CE, Barraclough J, et al. Cyclin D as a therapeutic target in cancer. Nat Rev Cancer 2011; 11: $558-72$

22. Lala N, Girish GV, Cloutier-Bosworth A, et al. Mechanisms in decorin regulation of vascular endothelia growth factor-induced human trophoblast migration and acquisition of endothelial phenotype. Biol Reprod 2012; 87: 59

23. Li P, Guo W, Du L, et al. microRNA-29b contributes to preeclampsia through its effects on apoptosis, invasion and angiogenesis of trophoblast cells. Clin Sci (Lond) 2013; 124: 27-40.

24. Nuzzo AM, Giuffrida D, Zenerino C, et al. JunB/cyclin-D1 imbalance in placental mesenchymal stromal cells derived from preeclamptic pregnancies with fetal-placental compromise. Placenta 2014; 35: 483-90.

25. Liu F, Wu K, Wu W, et al. miR-203 eontributes to pre-ec lampsia via inhibition of VEGFA expression. Mol Med Rep 2018; 17: 5627-34. 